Cochrane Database of Systematic Reviews

\title{
Botulinum toxin type A therapy for blepharospasm (Review)
}

Duarte GS, Rodrigues FB, Marques RE, Castelão M, Ferreira J, Sampaio C, Moore AP, Costa J

Duarte GS, Rodrigues FB, Marques RE, Castelão M, Ferreira J, Sampaio C, Moore AP, Costa J.

Botulinum toxin type $A$ therapy for blepharospasm.

Cochrane Database of Systematic Reviews 2020, Issue 11. Art. No.: CD004900.

DOI: 10.1002/14651858.CD004900.pub3.

www.cochranelibrary.com 
TABLE OF CONTENTS

HEADER 1

ABSTRACT

PLAIN LANGUAGE SUMMARY

SUMMARY OF FINDINGS

BACKGROUND

OBJECTIVES

METHODS

Figure 1.

RESULTS

Figure 2.

Figure 3.

DISCUSSION

AUTHORS' CONCLUSIONS

ACKNOWLEDGEMENTS

REFERENCES

CHARACTERISTICS OF STUDIES

DATA AND ANALYSES

Analysis 1.1. Comparison 1: Botulinum toxin type A (BtA) versus placebo, Outcome 1: Blepharospasm-specific severity .........

Analysis 1.2. Comparison 1: Botulinum toxin type A (BtA) versus placebo, Outcome 2: Blepharospasm-specific disability .......

Analysis 1.3. Comparison 1: Botulinum toxin type $A(B t A)$ versus placebo, Outcome 3: Adverse events

Analysis 1.4. Comparison 1: Botulinum toxin type A (BtA) versus placebo, Outcome 4: Vision complaints (diplopia, blurred vision, visual disturbance)

Analysis 1.5. Comparison 1: Botulinum toxin type A (BtA) versus placebo, Outcome 5: Eyelid ptosis

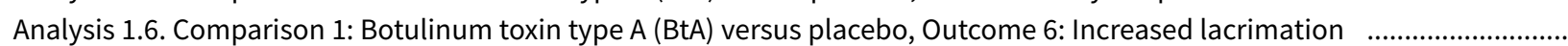

Analysis 1.7. Comparison 1: Botulinum toxin type $A(B t A)$ versus placebo, Outcome 7: Xerophthalmia

Analysis 1.8. Comparison 1: Botulinum toxin type A (BtA) versus placebo, Outcome 8: Frequency of blepharospasm-specific involuntary movements

Analysis 1.9. Comparison 1: Botulinum toxin type A (BtA) versus placebo, Outcome 9: Subjective participant evaluation ........

Analysis 1.10. Comparison 1: Botulinum toxin type A (BtA) versus placebo, Outcome 10: Tolerability - dropouts .................... APPENDICES

WHAT'S NEW

HISTORY

CONTRIBUTIONS OF AUTHORS

DECLARATIONS OF INTEREST

SOURCES OF SUPPORT

DIFFERENCES BETWEEN PROTOCOL AND REVIEW

INDEX TERMS 
[Intervention Review]

\section{Botulinum toxin type A therapy for blepharospasm}

Gonçalo S Duarte1,2a, Filipe B Rodrigues ${ }^{1,2 b}$, Raquel E Marques²,3, Mafalda Castelão1,2, Joaquim Ferreira1,2, Cristina Sampaio4 , Austen P Moore 5 , João Costa1,2

1Laboratory of Clinical Pharmacology and Therapeutics, Faculdade de Medicina da Universidade de Lisboa, Lisboa, Portugal. 2Instituto de Medicina Molecular João Lobo Antunes, Faculdade de Medicina da Universidade de Lisboa, Lisboa, Portugal. ${ }^{3}$ Ophthalmology University Clinic, Faculdade de Medicina da Universidade de Lisboa, Lisboa, Portugal. ${ }^{4}$ CHDI Foundation, Princeton, NJ, USA. ${ }^{5}$ The Walton Centre NHS Foundation Trust, Liverpool, UK

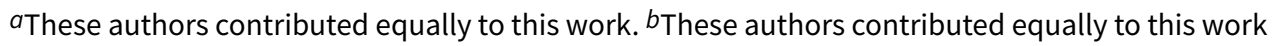

Contact address: João Costa, jncosta@medicina.ulisboa.pt.

Editorial group: Cochrane Movement Disorders Group.

Publication status and date: New search for studies and content updated (conclusions changed), published in Issue 11, 2020.

Citation: Duarte GS, Rodrigues FB, Marques RE, Castelão M, Ferreira J, Sampaio C, Moore AP, Costa J. Botulinum toxin type A therapy for blepharospasm. Cochrane Database of Systematic Reviews 2020, Issue 11. Art. No.: CD004900. DOI: 10.1002/14651858.CD004900.pub3.

Copyright $@ 2020$ The Cochrane Collaboration. Published by John Wiley \& Sons, Ltd.

\section{A B S T R A C T}

\section{Background}

This is an update of a Cochrane Review first published in 2005. Blepharospasm is the second most common form of focal dystonia. It is a disabling disorder, characterised by chronic, intermittent or persistent, involuntary eyelid closure, due to spasmodic contractions of the orbicularis oculi muscles. Currently, botulinum toxin type $A(B t A)$ is considered the first line of therapy for this condition.

\section{Objectives}

To compare the efficacy, safety, and tolerability of BtA versus placebo in people with blepharospasm.

\section{Search methods}

We searched Cochrane Movement Disorders' Trials Register, CENTRAL, MEDLINE, Embase, reference lists of included articles, and conference proceedings. We ran all elements of the search, with no language restrictions, in July 2020.

\section{Selection criteria}

Double-blind, parallel, randomised, placebo-controlled trials (RCTs) of BtA versus placebo in adults with blepharospasm.

\section{Data collection and analysis}

Two review authors independently assessed records, selected included studies, extracted data using a paper pro forma, and evaluated the risk of bias. We resolved disagreements by consensus, or by consulting a third review author. We performed meta-analyses using a randomeffects model, for the comparison of BtA versus placebo, to estimate pooled effects and corresponding $95 \%$ confidence intervals ( $95 \% \mathrm{Cl}$ ). We did not carry out any prespecified subgroup analyses. The primary efficacy outcome was improvement on any validated symptomatic rating scale. The primary safety outcome was the proportion of participants with any adverse event.

\section{Main results}

We included three RCTs, assessed at low to moderate overall risk of bias, which randomised 313 participants with blepharospasm. Two studies excluded participants with poorer prior responses to BtA treatment, therefore, they included an enriched population with a higher probability of benefiting from this therapy. All trials were industry-funded. All RCTs evaluated the effect of a single BtA treatment session.

BtA resulted in a moderate to large improvement in blepharospasm-specific severity, with a reduction of 0.93 points on the Jankovic Rating Scale (JRS) severity subscale at four to six weeks after injection ( $95 \%$ confidence interval (CI) 0.61 to $\left.1.25 ; I^{2}=9 \%\right)$ compared to placebo. 
BtA was also resulted in a moderate to large improvement in blepharospasm-specific disability and blepharospasm-specific involuntary movements at four to six weeks after injection (disability: $0.69 \mathrm{JRS}$ disability subscale points, $95 \% \mathrm{Cl} 0.18$ to 1.19 ; $\left.\right|^{2}=74 \%$; blepharospasmspecific involuntary movements: standardised mean difference (SMD) $0.79,0.31$ to $1.27 ; \mathrm{I}^{2}=58 \%$ ) compared to placebo. BtA did not show a risk of adverse events (risk ratio (RR) $1.18,95 \% \mathrm{Cl} 0.87$ to $1.60 ; \mathrm{I}^{2}=0 \%$ ). However, BtA increased the risk of vision complaints and eyelid ptosis (vision complaints: RR 5.73, 95\% Cl 1.79 to 18.36 ; $I^{2}=51 \%$; eyelid ptosis: $\mathrm{RR} 4.02,95 \% \mathrm{Cl} 1.61$ to $10.00 ; \mathrm{I}^{2}=39 \%$ ). There was no distinction between BtA and placebo in the number of participants who dropped out of the trial.

A single trial estimated the duration of effects to be 10.6 weeks (range 6.1 to 19.1).

We found no evidence supporting the existence of a clear dose-response relationship with BtA. We found no data reporting the impact of $\mathrm{BtA}$ on health-related quality of life, or the development of secondary non-responsiveness.

\section{Authors' conclusions}

We are moderately certain that a single BtA treatment resulted in a clinically relevant reduction of blepharospasm-specific severity and disability, and have low certainty that it is well tolerated, when compared with placebo. There is low-certainty evidence that people treated with BtA are not at an increased risk of developing adverse events, though BtA treatment likely increases the risk of visual complaints and eyelid ptosis. There are no data from RCTs evaluating the effectiveness and safety of repeated BtA injection cycles.

There is no evidence from RCTs to allow us to draw definitive conclusions on the optimal treatment intervals and doses, or the impact on quality of life.

\section{PLAIN LANGUAGE SUMMARY}

\section{Botulinum toxin type A for people with involuntary eyelid closure, or blepharospasm}

\section{The review question}

We reviewed the evidence about the effect of botulinum toxin type $A(B t A)$ in people with involuntary eyelid closure, or blepharospasm. This is an update of a previous Cochrane Review and we assessed the effectiveness and safety of BtA versus placebo (a pretend medicine) in blepharospasm.

\section{Background}

Blepharospasm is a dysfunction of the eyelids that presents as involuntary eyelid closure, due to contractions of the eye muscles. Botulinum toxin type A (BtA) is a powerful, natural chemical that can cause severe paralysis (an inability to move the part of the body in which it is injected) in animals and humans. It can also be used to treat many conditions, in particular, those with involuntary muscle contractions, such as blepharospasm. Botulinum toxin is delivered by injections into the muscles that contract to produce most of the disorder-related symptoms. There are different types of botulinum toxin, not all are available for treating health conditions. BtA is typically considered the first main treatment option for people with blepharospasm.

\section{Study characteristics}

We searched the medical literature in July 2020 and found three studies that compared treatment with BtA with placebo (injection with a liquid that will not treat the problem). These studies included a total of 313 participants, who had, on average, a moderate impairment. Most (66\%) of the people in the studies were women. All trials were funded by drug manufacturers with possible interests in the results of the studies.

\section{Key results}

The results show that a single treatment session (where both eyelids were injected with BtA multiple times) improved the severity of blepharospasm symptoms, disability, and number of involuntary movements. We did not find an increased risk of any unpleasant or undesirable event, though we did find a larger risk of vision complaints and eyelid drooping in people who took BtA. Participants felt that BtA was better than placebo. The BtA effect lasted for around 10 weeks. No study examined the effect of BtA on quality of life.

\section{Certainty in the evidence}

The certainty in the evidence varies from low to high. We can draw no conclusions regarding long-term effects of BtA for this condition. 


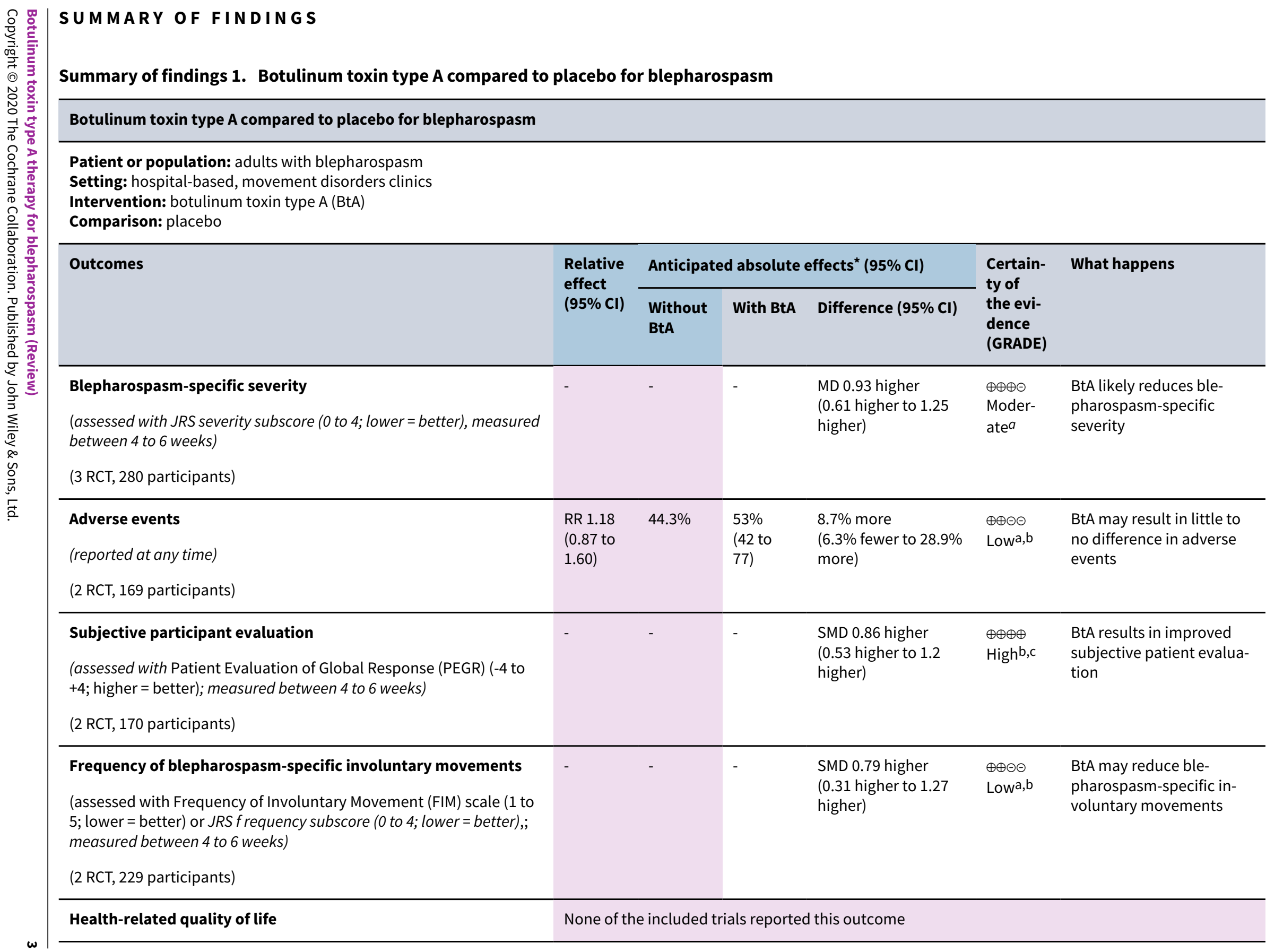




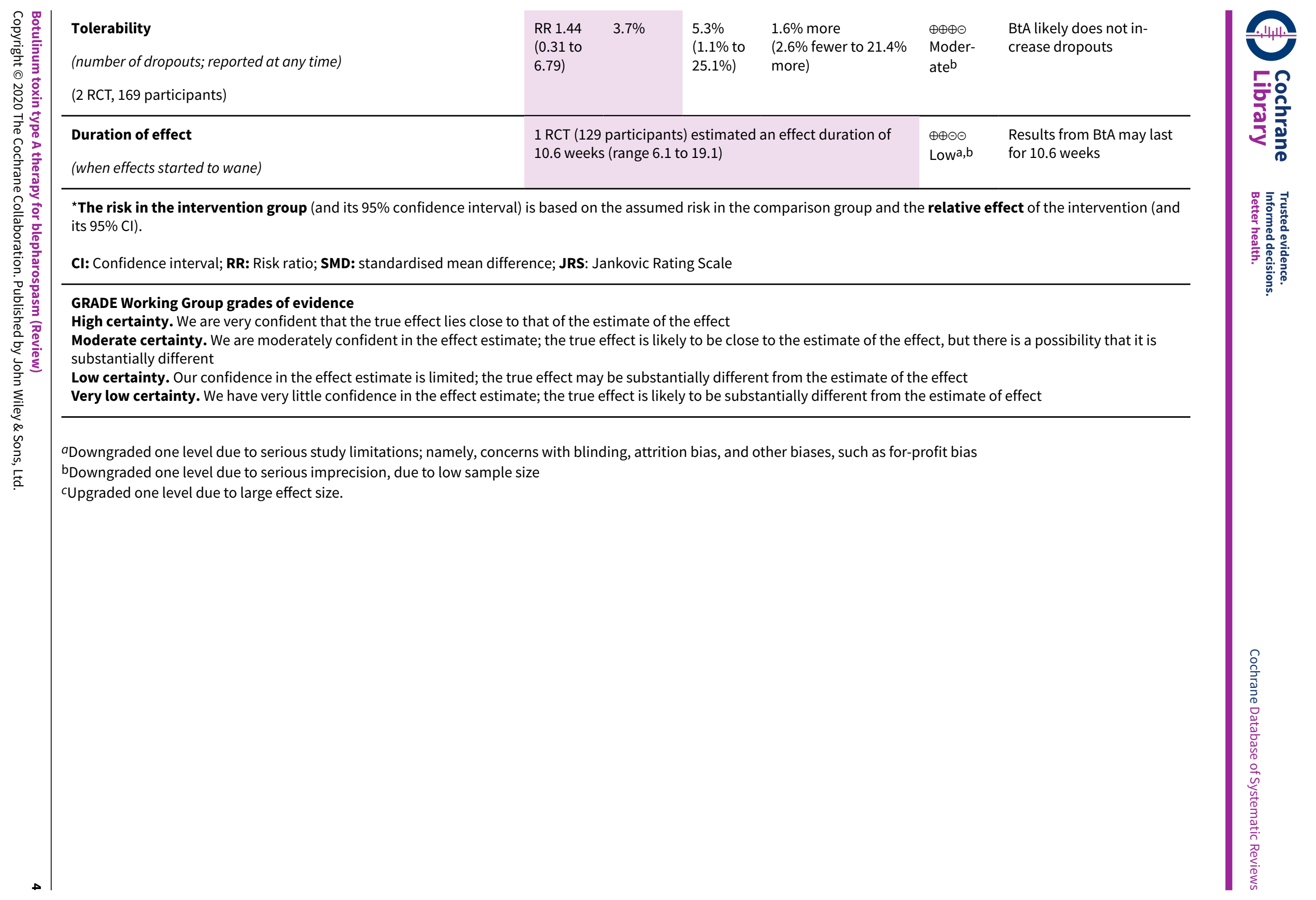




\section{B A C K G R O U N D}

This is an update of a Cochrane Review first published in 2005 (Costa 2005).

\section{Description of the condition}

Dystonia is the third most common movement disorder, after Parkinson's disease and essential tremor, with an overall prevalence of 164 per million (Steeves 2012). Dystonia syndromes are a group of disabling, painful disorders characterised by involuntary sustained or intermittent muscle contractions causing abnormal, often repetitive, movements or postures of the face, neck, trunk, or limbs (Albanese 2013). Dystonic movements are typically patterned or twisting, and are often initiated or worsened by voluntary action (Albanese 2013). These neurological disorders can be classified, based on topographic distribution, including focal dystonia (one body region, e.g. cervical dystonia and blepharospasm), segmental dystonia (two or more adjacent regions), multifocal dystonia (two or more nonadjacent regions), hemidystonia (ipsilateral regions), and generalised dystonia (trunk and two or more other regions (Albanese 2013; Tarsy 2006)).

Focal dystonia is a highly disabling movement disorder, with serious functional and social impairment. Close to half of the people with it quit work by the age of forty, or retire early, and 10 years later, only $25 \%$ of people are working compared to $62 \%$ of the general population (Zoons 2012). Moreover, health-related quality of life is significantly diminished, mainly attributable to depression and anxiety, with scores comparable to people with multiple sclerosis, Parkinson's disease, or stroke (Zoons 2012).

Blepharospasm is a focal dystonia characterised by chronic intermittent or persistent involuntary eyelid closure due to spasmodic contractions of the orbicularis oculi muscles (Berardelli 1985; Elston 1988; Grandas 1988; Jankovic 1982a; Marsden 1976; Tolosa 1988). Sometimes, there is additional involuntary inhibition of the levator palpebrae superioris muscle (Aramideh 1994). The term essential blepharospasm is used to describe involuntary contractions involving only the orbital and periorbital muscles. However, many people also have spasms of other facial, oromandibular, pharyngeal, laryngeal, or cervical muscles (Tolosa 1979). When adjacent body regions are involved, this form of segmental dystonia is referred to as cranial cervical dystonia.

Neurophysiological studies support the hypothesis that blepharospasm is due to hyperexcitability of brainstem interneurons, as a result of organic dysfunction of the basal ganglia (Grandas 1988; Grandas 1998). The vast majority of cases are idiopathic. Exposure to neuroleptics is a known risk factor for dystonia and blepharospasm. Rarely, lesions in the basal ganglia and upper midbrain (e.g. with stroke, multiple sclerosis, hydrocephalus) have been associated with blepharospasm. Cranial cervical dystonia can also occur in association with other diseases and disorders of the central nervous system, such as Wilson's disease, Parkinson's disease, and progressive supranuclear palsy (Cardoso 1995).

The prevalence of blepharospasm is estimated to be 5 per 100,000 (Grandas 1988; Nutt 1988). It usually begins late in life, during the fifth or sixth decade, and affects women more often than men (Frueh 1976; Grandas 1988; Henderson 1956; Jankovic 1983; Marsden 1976; Tolosa 1981). Typically, it starts with an increased frequency of blinking to a variety of stimuli, such as air pollution, bright light, and stress. It progresses to chronic, involuntary spasm involving both eyes synchronously (Jankovic 1982b). Its severity can range from repeated frequent blinking to persistent spasmodic closure of the eyelids, leading to functional blindness, with severe private and professional disability (Jankovic 1982a; Tucha 2001).

To date, no curative or disorder-modifying treatments are available for blepharospasm.

\section{Description of the intervention}

Botulinum toxin is a powerful biological toxin produced by Clostridium botulinum. The active form of botulinum toxin is a dichain polypeptide composed of two chains: a heavy chain (100 $\mathrm{kDa})$ and a light chain $(50 \mathrm{kDa})$, and by associating with certain auxiliary proteins (haemagglutinins and non-haemagglutinins), the toxin forms a non-covalent multimeric complex of variable size (Simpson 2004). The nontoxic proteins aid the formation of neutralising antibodies, though beyond this, their role is unclear (Frevert 2010). Botulinim toxin binds to peripheral cholinergic nerve terminals of the neuromuscular junction, as well as sympathetic ganglionic, parasympathetic ganglionic, and postganglionic terminals (Simpson 2004). After binding to an acceptor protein, botulinum toxin is endocytosed at the presynaptic membrane of acetylcholine nerve terminals (Pellizzari 1999). By action of the N-terminal on the heavy chain, a pore is formed on the endocytic membrane, which permits the release of the light chain into the cytosol. This light chain, which is a zinc protease, performs the key action of the botulinum toxin, by cleaving soluble $\mathrm{N}$-ethylmaleimide-sensitive factor attachment receptor proteins (SNARE proteins; (Pellizzari 1999)).

SNAREs are docking proteins for acetylcholine vesicles that allow for the release of acetylcholine into the synaptic cleft (Pellizzari 1999). The overall effect of botulinum toxin is a local chemodenervation by the temporary blockade of acetylcholine release at cholinergic synapses. Temporary synapses are consequently formed via the process of axonal sprouting (Duchen 1971; Holland 1981; Juzans 1996).

There are seven immunologically distinct botulinum toxin serotypes (labelled $A$ to $G$ ). These different botulinum toxin serotypes cleave specific SNARE proteins. Serotype A cleaves SNARE protein SNAP 25, located on the inner membrane of nerve cells (Pellizzari 1999).

Botulinum toxin is injected into the muscles thought to be involved in dystonia. As a general rule, the number of muscles injected are tailored to the severity of the case in question, and the number of injection sites per muscle are determined by the mass of the muscle. Within roughly three months after injection of botulinum toxin into skeletal muscle, the nerve terminal resumes exocytosis, and the muscle returns to its baseline clinical function, showing a wearing-off response from the botulinum toxin injection (Jankovic 2004). Eventually, the muscle paralysis subsides; this is associated with the formation of new sprouts that are capable of neurotransmission. Over time, synaptic activity resumes in the original nerve terminals, leading to sprout regression (de Paiva 1999).

Currently, there are two commercially available botulinum toxin serotypes - botulinum toxin type $A(B t A)$ and botulinum 
toxin type $B(B t B)$. The following products are commonly available (three $\mathrm{BtA}$ and one $\mathrm{BtB}$ ): onabotulinumtoxinA (Botox, Allergan Inc., Irvine, CA, USA), abobotulinumtoxinA (Dysport or Reloxin or Azzalure, Ipsen Pharma, Boulogne Billancourt, France), incobotulinumtoxinA (Xeomin or Bocoture Merz GmbH, Frankfurt, Germany), and rimabotulinumtoxinB (Myobloc or Neurobloc, Solstice Neurosciences Inc., Louisville, KY, USA). Other BtA formulations are available in more restricted markets, and are yet to receive a generic name: Prosigne or Lantox (Lanzhou Institute of Biological Products, China), PurTox (Mentor Worldwide LLC, Santa Barbara, CA, USA), and Neuronox (Medy-Tox Inc, South Korea; (Walker 2014)).

\section{How the intervention might work}

The therapeutic potential of all botulinum toxin serotypes derives from their ability to inhibit the release of acetylcholine from the presynaptic nerve terminal into the synaptic cleft, causing local chemodenervation (Jankovic 2004). In addition to this, recent research has also suggested that botulinum toxin is active at multiple levels, namely sensory nerve terminals, and muscle spindles, which leads to a reduction in sensory input and fewer muscle contractions (Filippi 1993; Matak 2014; Rosales 1996; Rosales 2010).

It has been further suggested that cortical reorganisation may result from changes in the spinal cord, brainstem, and central nervous pathways (Palomar 2012). Animal research has shown the presence of supra-therapeutic levels of botulinum toxin by way of retrograde axonal transport and penetration of the CNS (Antonucci 2008; Boroff 1975). However, botulinum toxin has not been shown to penetrate the blood-brain barrier in humans.

Until recently, SNARE proteins were considered the only target molecules of botulinum toxin. Thus, it was widely accepted that the therapeutic and toxic actions of botulinum toxin were exclusively mediated by SNARE cleavage preventing the release of synaptic neurotransmitters. However, recent studies have suggested that a number of botulinum toxin actions might not be mediated by SNARE cleavage, specifically regarding neuroexocytosis, cell cycle and apoptosis, neuritogenesis, and gene expression (Matak 2015). The existence of unknown botulinum toxin molecular targets and modulation of unknown signalling pathways is a possibility that may prove to be pharmacologically relevant.

\section{Why it is important to do this review}

BtA is the toxin serotype that has been most intensively studied and approved for the treatment of a large number of focal dystonias. Both BtA and BtB have been shown to be efficacious in cervical dystonia (Castelão 2017; Marques 2016; Duarte 2016), and for hemifacial spasm (Costa 2005a). However, even in moderate-severity dystonia, there is evidence that people attach a considerable expectation of harm due to botulinum toxin, the so called nocebo effect (Duarte 2018).

This is an update of a Cochrane Review that aimed to assess the efficacy and safety of BtA in comparison to placebo in people with blepharospasm. The original review failed to identify evidence from randomised controlled trials to support the use of BtA for blepharospasm. Since its publication, three new trials have been published (Jankovic 2011; Mitsikostas 2018; Truong 2008). Cochrane's criteria for evaluating studies' risk of bias and the certainty in evidence have also evolved and been updated. Therefore, the authors considered it important to update this review.

\section{O B JECTIVES}

To compare the clinical efficacy, safety, and tolerability of botulinum toxin type $\mathrm{A}(\mathrm{BtA})$ versus placebo in the treatment of adults with blepharospasm

\section{METHODS}

\section{Criteria for considering studies for this review Types of studies}

Randomised controlled trials (RCTs), blinded, single, or multiple dose, parallel-designed, of any duration, assessing the efficacy or safety, or both, of botulinum toxin type $A(B t A)$ treatment versus placebo, in people with blepharospasm, were eligible for inclusion in this review. We excluded non-parallel study designs, namely cross-over trials, due to uncertainty about whether this type of study design was appropriate to study people with blepharospasm, as well as methodological concerns with regards to detection and performance bias.

There were no restrictions regarding the number of participants recruited to trials, or the number of recruitment centres.

\section{Types of participants}

Adults (i.e. 18 years of age or older), in any setting, with a clinical diagnosis of blepharospasm, made by a physician, specialist, or other healthcare provider. We included trials enrolling participants with any form of blepharospasm, with or without widespread dystonias. We included participants with prior exposure to botulinum toxin, or those taking concomitant medications, if they were on stable regimens.

\section{Types of interventions}

Intramuscular injections of botulinum toxin type A (BtA) compared to placebo. We allowed all administration schedules and injection techniques.

\section{Types of outcome measures \\ Primary outcomes}

\section{Blapherospasm-specific improvement}

Overall improvement, measured on any validated symptomatic rating scale, such as Jankovic Rating Scale, measured between weeks three and six.

\section{Adverse events}

The proportion of participants with any adverse event, measured at any point during study follow-up. For this outcome, we also evaluated adverse events of special interest, such as sore throat or dry mouth, neck weakness, dysphagia, injection site pain, voice change, and systemic complaints (e.g. diffuse muscle weakness, malaise, dizziness, and headache), measured at any point during study follow-up. 


\section{Secondary outcomes}

\section{Subjective evaluation of clinical status}

Evaluated by either participants, or clinicians, or both, and assessed with validated assessment tools, such as Patient Subjective Assessment of Change, Patient Global Assessment of Improvement, Patient Evaluation of Global Response (PEGR), Patient and Physician Global Assessment of Change, Investigator Global Assessment of Efficacy (IGAE), Physician Global Assessment of Change (PGAC), and visual analogue scale (VAS) for symptom severity, measured between weeks three and six.

\section{Frequency of blepharospasm-specific involuntary movements}

Measured between weeks three and six.

\section{Health-related quality of life}

Assessed with validated assessment tools, such as Short Form 36 (SF-36) Quality of Life questionnaire, measured at any point during study follow-up.

\section{Tolerability}

We defined tolerability as the number of participants who discontinued treatment (dropouts) due to adverse events, measured at any point during study follow-up.

\section{Duration of effect}

Assessed by the number of days until the need for reinjection, or waning of effect.

\section{Search methods for identification of studies}

For this update, we expanded the search strategy to capture all the search terms for BtA formulations that were currently available. We designed the search strategy to include other botulinum toxin formulations and other dystonic disorders that are also under current revision the Movement Disorders Cochrane Review Group.

\section{Electronic searches}

We ran the final search for the original version of this review in June 2003, based on the search strategy developed for Cochrane Movement Disorders to identify all papers since 1977, the first year that botulinum toxin was used therapeutically in any condition. We ran the search for the current update for the last time in July 2020.

For the identification of studies considered for inclusion in this review, we developed detailed search strategies for each database searched. Please see Appendix 1 for the Cochrane Central Register of Controlled Trials (CENTRAL) strategy, Appendix 2 for the MEDLINE search strategy, and Appendix 3 for the Embase strategy.

We assessed non-English language papers, translated them as necessary, and evaluated them for inclusion.

We did not search trials registries.

\section{Databases searched}

- Cochrane Movement Disorders' Trials Register (July 2020);

- CENTRAL (2020, Issue 6) in the Cochrane Library, (searched July 2020);

- MEDLINE (1977 to July 2020);

- Embase (1977 to July 2020).

\section{Searching other resources}

The search strategy also included:

- searches of reference lists of located trials and review articles concerning botulinum toxin;

- handsearch of abstracts of international congresses relevant to the fields of movement disorders and botulinum toxins (American Academy of Neurology, Movement Disorders Society, International Association of Parkinsonism and Related Disorders, and International Neurotoxin Association (1985 to July 2020));

- personal communication with other researchers in the field;

- contact with drug manufacturers;

- whenever necessary, we contacted authors of published trials for further information and unpublished data.

\section{Data collection and analysis}

\section{Selection of studies}

Two review authors independently screened all titles and abstracts identified from searches to determine which ones met the inclusion criteria. We retrieved in full text any papers identified as potentially relevant by at least one review author, or those without an available abstract. Two review authors independently screened full-text articles, with discrepancies resolved by discussion, and by consulting a third review author, where necessary, to reach consensus. We collated duplicate publications and presented our references by individual study. We outlined the screening and selection process in a PRISMA flow chart (Liberati 2009); see Figure 1. 
Figure 1. Flow diagram for study selection

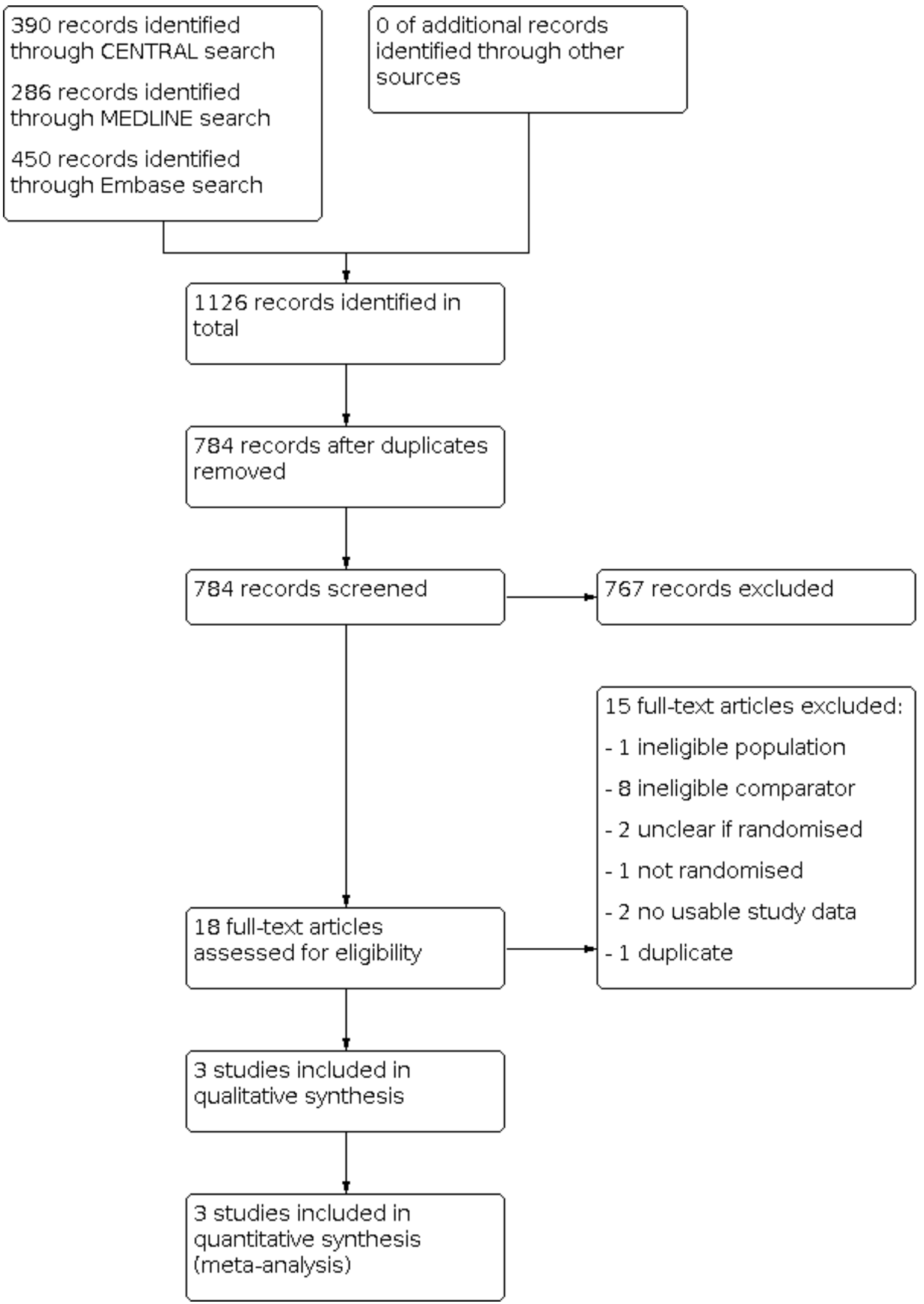




\section{Data extraction and management}

Two review authors independently extracted data from included studies, using a piloted data extraction form. We resolved any discrepancies by discussion, until consensus was reached, or through consultation with a third review author, where necessary. Data extracted included the following items from each study.

- Participants: inclusion and exclusion criteria, demographics and clinical baseline characteristics, number and reasons for dropping out, exclusions, and loss to follow-up, if any

- Interventions: full description of intervention, duration of treatment period and follow-up, providers, and cointerventions, if any

- Comparisons: number of randomised participants to each arm, compliance and number of dropouts, reasons for dropping out, and ability to perform an intention-to-treat analysis

- Outcomes: definition of outcomes, use of validated measurement tools, time point measurements, change from baseline or post-interventional measures, and missing outcomes, if any

- Study design: interventional, randomised, controlled, doubleblind.

\section{Assessment of risk of bias in included studies}

We assessed the risk of bias of included studies according to the domains described in the Cochrane tool for assessing risk of bias, and classified the risk of bias for each domain as high, unclear, or low, and the overall assessment as high or low (Higgins 2011a). We assessed two further domains, which are described below: enriched population and independent funding. We used the following definitions for each domain in the 'Risk of bias' assessment.

- Random sequence generation (checking for possible selection bias). We assessed the method used to generate the allocation sequence as: low risk of bias (any truly random process, e.g. random number table; computer random number generator); unclear risk of bias (method used to generate sequence not clearly stated); high risk of bias (non-random process used, e.g. allocation by birth year or by judgement).

- Allocation concealment (checking for possible selection bias). We assessed the method used to conceal allocation to interventions prior to assignment, to determine whether intervention allocation could have been foreseen in advance of, or during recruitment, or changed after assignment. We assessed the methods as: low risk of bias (e.g. telephone or central randomisation; consecutively numbered, sealed, opaque envelopes); unclear risk of bias (method not clearly stated); high risk of bias (e.g. open list).

- Blinding of participants and personnel (checking for possible performance bias). We assessed the methods used to blind study participants and personnel from knowledge of which intervention a participant received. We assessed methods as: low risk of bias (study stated that it was blinded and described the method used to achieve blinding, such as identical tablets matched in appearance or smell, or a doubledummy technique); unclear risk of bias (study stated that it was blinded but did not provide an adequate description of how it was achieved). Studies that were not double-blind were considered to have high risk of bias.
- Blinding of outcome assessment (checking for possible detection bias). We assessed the methods used to blind outcome assessors from knowledge of which intervention a participant received. We assessed the methods as: low risk of bias (study had a clear statement that outcome assessors were unaware of treatment allocation, and ideally described how this was achieved); unclear risk of bias (study stated that outcome assessors were blind to treatment allocation but lacked a clear statement on how it was achieved). We considered studies where outcome assessment was not blinded as having a high risk of bias.

- Selective reporting (checking for reporting bias). We assessed whether primary and secondary outcome measures were prespecified, and whether these were consistent with those reported. We assessed selective reporting as: low risk of bias (studies reporting results for primary and secondary outcomes); unclear risk of bias (study reporting insufficient information to permit judgement); high risk of bias (not all pre-specified outcomes reported, or only reported for certain data collection time points).

- Incomplete outcome data (checking for possible attrition bias due to the amount, nature, and handling of incomplete outcome data). We assessed the methods used to deal with incomplete data as: low risk $(<10 \%$ of participants did not complete the study, trial authors used 'baseline observation carried forward' analysis, or both); unclear risk of bias (used 'last observation carried forward' analysis); high risk of bias (used 'completer' analysis).

In addition to these criteria, we also added two more items for consideration.

- Enriched population. Because the clinical effect of botulinum toxin treatment is easily perceived, participants not naive to botulinum toxin are likely to recognise the presence or absence of beneficial clinical effects, or frequent adverse events, or both, effectively revealing the respective allocation arm. It is also relevant that by preferentially including responders to botulinum toxin or excluding non-responders to botulinum toxin, there is an increased likelihood that these participants would respond more favourably to botulinum toxin than a naive population would. We opted to subdivide this domain in two: preferential enrolment of known positive responders to botulinum toxin; and exclusion of known poor responders to botulinum toxin.

* Low risk of bias: at least $70 \%$ of trial participants were naive to treatment with botulinum toxin; the trial did not exclude any particular form of blepharospasm.

* Unclear risk of bias: the trial did not make explicit the percentage of participants who were known to be naive to botulinum toxin.

* High risk of bias: arbitrarily defined as more than $30 \%$ of participants who were not naive to botulinum toxin; explicit exclusion of people with forms of blepharospasm associated with a poorer response to botulinum toxin. 
- For-profit bias. In order to assess the study source of funding, we added this domain

* Low risk of bias: the trial appeared to be free of industry sponsorship or other types of for-profit support that may introduce bias into trial design, conduct, or trial results.

* Unclear risk of bias: the trial may or may not be free of forprofit bias, as the trial did not provide any information on clinical trial support or sponsorship.

* High risk of bias: the trial was sponsored by industry or received other type of for-profit support.

\section{Measures of treatment effect}

We compared disorder-related symptoms at baseline to symptoms in weeks four to six post-injection in the BtA and placebo arms. We extracted continuous outcomes whenever possible, pooled the data from the studies, where adequate, and used them for comparison.

\section{Dichotomous data}

We based analysis of these data on the number of events and the number of people assessed in the intervention and comparison groups. We used these to calculate the risk ratio (RR) and 95\% confidence interval $(\mathrm{Cl})$.

\section{Continuous data}

We based analysis of these data on the mean, standard deviation (SD), and number of people assessed for both the intervention and comparison groups to calculate mean difference (MD) and $95 \% \mathrm{Cl}$. Where the MD was reported without individual group data, we used this to report the study results. If more than one study measured the same outcome using different validated tools, we calculated the standardised mean difference (SMD), namely Hedges' (adjusted) g, and $95 \% \mathrm{Cl}$ (Hedges 1985). For interpretation of effect sizes with SMDs, we used a rule of thumb to define a small effect (SMD = $0.2)$, a moderate effect $(S M D=0.5)$, or a large effect $(S M D=0.8$; (Cohen 1988)). If necessary for comparison, we dichotomised rating scales using each study author's own criteria for improvement or no improvement.

\section{Time-to-event data}

We planned to analyse these data based on log hazard ratios (HR) and standard errors (SE) obtained from results of Cox proportional hazards regression models. We had planned to use these in order to calculate a $\mathrm{HR}$ and $95 \% \mathrm{Cl}$.

\section{Unit of analysis issues}

Whenever the included studies had multiple arms with different doses of botulinum toxin, we combined all groups to create a single pair-wise comparison, using the Review Manager 5 calculator, according to the methods suggested by Cochrane (Higgins 2011b; Review Manager 2014). We also would have opted to create a single, pair-wise comparison in cases when multiple treatment groups, using different interventions (e.g. onabotulinumtoxinA and abobotulinumtoxinA), were compared to the same comparator.

This method combines all relevant experimental intervention groups of the study into a single group, and all relevant control intervention groups into a single control group. This approach avoids the duplication of the control group, which would happen if multiple comparisons (e.g. BtA dose 1 versus placebo; BtA dose
2 versus placebo) were included in the meta-analysis, as well as the loss of information if one dose group is chosen over the others. If applicable, we plan to explore the effect of dose in subgroup analysis.

For dichotomous outcomes, we planned to sum both the sample sizes and the numbers of people with events across groups. For continuous outcomes, we planned to pool means and standard deviations in a meta-analysis (Higgins 2011b; Higgins 2011c).

\section{Dealing with missing data}

For missing outcome or summary data, we used imputation methods to derive the missing data (where possible), and reported any assumptions in the review. In these cases, we carried out sensitivity analyses to investigate the effects of any imputed data on pooled effect estimates.

As the first option, we used the available information (e.g. standard error (SE), $95 \% \mathrm{Cl}$, or exact $\mathrm{P}$ value) to recover the missing data algebraically (Higgins 2011b; Higgins 2011c; Wiebe 2006). When change from baseline SD data were not reported, or we were unable to extract them, we attempted to create a correlation coefficient, based on another study in the review, and then used this correlation coefficient to impute a change from baseline SD (Abrams 2005; Follmann 1992; Higgins 2011b).

If this failed, and there was at least one sufficiently large and similar study, we planned to use a method of single imputation (Furukawa 2006; Higgins 2011b).

Lastly, if there were a sufficient number of included studies with complete information, we planed to use multiple imputation methods to derive missing data (Carpenter 2013; Rubin 1991).

If none of these methods proved successful, we planned to conduct a narrative synthesis for the data in question.

\section{Assessment of heterogeneity}

We assessed whether studies were similar enough to allow pooling of data using meta-analysis. Where data were pooled using metaanalysis, we assessed the degree of heterogeneity by visual inspection of forest plots and by examining the $\mathrm{Chi}^{2}$ test for heterogeneity (Deeks 2011). We quantified heterogeneity using $I^{2}$ (Higgins 2003). We considered an $I^{2}$ value of $50 \%$ or more to represent substantial levels of heterogeneity, but interpreted this value in light of the size and direction of effects, and the strength of the evidence for heterogeneity, based on the $\mathrm{P}$ value from the $\mathrm{Chi}^{2}$ test.

\section{Assessment of reporting biases}

We included too few studies in this review, i.e. fewer than 10 , to allow construction of a funnel plot (Sterne 2001), and formal testing of asymmetry, which may indicate publication bias (Peters 2006). Should enough studies be included in future updates of this review, we plan to undertake these analyses.

\section{Data synthesis}

We performed the analyses with Review Manager 5 (Review Manager 2014), Stata version 15 (Stata), and Trial Sequential Analysis (TSA; (Thorlund 2011; TSA 2011)). 


\section{Meta-analysis}

We based the decision of whether or not to meta-analyse data on an assessment of whether the interventions in the included trials were similar enough in terms of participants, settings, intervention, comparison, and outcome measures to ensure meaningful conclusions from a statistically pooled result. We conducted data synthesis using a random-effects model.

We pooled effect measures by applying the Mantel-Haenszel method for dichotomous outcomes, and applied the inversevariance or generic inverse-variance method for continuous outcomes. We had planned to pool time-to-event data using the generic inverse-variance method. We presented all results with 95\% $\mathrm{Cl}$.

We calculated the number of participants needed to treat for an additional beneficial outcome (NNTB) and for an additional harmful outcome (NNTH) from meta-analysis estimates, rather than treating data as if they came from a single trial, as the latter approach is more prone to bias, especially when there are significant imbalances between groups within one or more trials in the meta-analysis (Altman 2002). However, caution is needed in the interpretation of these findings, since they may be misleading because of variation in the event rates in each trial, differences in the outcomes considered, and differences in clinical settings (Smeeth 1999).

Where there were no data that could be combined in a metaanalysis, we undertook a narrative approach to result synthesis.

\section{Assessing the certainty in the evidence}

As recommended by the GRADE Working Group methodology, two review authors independently assessed all of the outcomes in the following domains: study limitations, inconsistency, indirectness, imprecision, and publication bias (Schünemann 2011). In case of disagreement, the review authors attempted to reach consensus, consulting an independent third review author if necessary. For this purpose, we used the GRADEpro GDT software tool, which we then used to export a 'Summary of findings' table into the review text (GRADEpro GDT).

To ensure the consistency and reproducibility of GRADE judgements, we applied the following criteria to each outcome.

- Study limitations: we downgraded once if more than $30 \%$ of participants were from studies classified as being at a high risk of bias across any domain, with the exception of for-profit bias.

- Inconsistency: we downgraded once if heterogeneity was statistically significant, or if the $\mathrm{I}^{2}$ value was more than $40 \%$. When we did not perform a meta-analysis, we downgraded once if trials did not show effects in the same direction.

- Indirectness: we downgraded once if more than $50 \%$ of the participants were outside the target group.

- Imprecision: we downgraded once if the optimal information size was not met, or alternatively, if it was met but the $95 \% \mathrm{Cl}$ failed to exclude important benefit or important harm (Guyatt 2011).

- Publication bias: we downgraded once if there was direct evidence of publication bias, or if estimates of effect were based on small scale, industry-sponsored studies, which raised a high index of suspicion of publication bias.
We applied the following definitions to the certainty in the evidence (Balshem 2011):

- high certainty: we are very confident that the true effect lies close to that of the estimate of the effect;

- moderate certainty: we are moderately confident in the effect estimate; the true effect is likely to be close to the estimate of the effect, but there is a possibility that it is substantially different;

- low certainty: our confidence in the effect estimate is limited; the true effect may be substantially different from the estimate of the effect;

- very low certainty: we have very little confidence in the effect estimate; the true effect is likely to be substantially different from the estimate of effect.

\section{'Summary of findings' table}

We included a 'Summary of findings' table to present the main findings of this review in a simple tabular format, based on the results of the GRADE analysis. Version 3 was used for ease of interpretation (Carrasco-Labra 2016).

\section{Subgroup analysis and investigation of heterogeneity}

We planned subgroup analyses for the following areas, independently of the presence of significant heterogeneity.

- Different BtA formulations

- Different BtA doses, all defined arbitrarily: high (Botox or Xeomin $>200 \mathrm{U}$; Dysport $=1000 \mathrm{U}$ ), medium (Botox or Xeomin $100 \mathrm{U}$ to $200 \mathrm{U}$; Dysport $=500 \mathrm{U}$ ), and low (Botox or Xeomin < $100 \mathrm{U}$; Dysport $=250 \mathrm{U}$

\section{Sensitivity analysis}

We conducted sensitivity analyses for every study for which we applied imputation methods.

\section{RES U L T S}

\section{Description of studies}

We identified three new studies for inclusion in this update (Jankovic 2011; Mitsikostas 2018; Truong 2008).

These were parallel-designed studies comparing botulinum toxin type A (BtA; different total treatment doses) with placebo, with a total of 313 participants with blepharospasm.

See also Characteristics of included studies.

\section{Results of the search}

See: Figure 1, flow diagram of study selection.

We last ran the electronic search in July 2020. The search returned 1126 records (390 through CENTRAL; 286 though MEDLINE; 450 through Embase), resulting in 784 records after removing all duplicates. After title and abstract screening, we assessed 18 articles for full-text screening. We included three for both the qualitative and quantitative syntheses.

We excluded one trial for including participants in which the blepharospasm was part of a more complex syndrome (Jankovic 1987),; eight for not including a placebo group; two for possibly not being randomised (Fahn 1985; Girlanda 1996); two for not being 
randomised (Aramideh 1995; Jankovic 1995); another two without usable study data (Frueh 1988; Park 1993); and one for being a duplicate of an included study (Pagan 2018).

\section{Included studies}

See Characteristics of included studies.

The three trials enrolled a total of 313 adult participants, with a mean age of 61.2 years (range 18 years to 82 years), 208 of whom were female (66\%). Sample size varied from 61 to 129 participants. All were multicentre trials.

Participants' baseline characteristics differed between trials. The mean duration of blepharospasm was only reported in one trial 233 months in the BtA arm and 278 months in the placebo arm (Jankovic 2011).

The overall disorder-related impairment at baseline was moderate to severe in Jankovic 2011, with an average total Jankovic Rating Scale (JRS) score of 5.87 in the BtA arm and 5.76 in the placebo arm. The other two trials did not report any impairment information.

Only Mitsikostas 2018 exclusively enrolled participants who had never been exposed to botulinum toxin, and did not enrich the trial population by excluding participants with clinical forms of blepharospasm associated with a poorer response to botulinum toxin. We deemed both other studies to be at high risk of bias for this domain. As a result, the population characteristics across studies did not allow us to conduct a subgroup analysis for people naive and non-naive to botulinum toxin. Overall, the number of dropouts was low in both trials that reported this outcome, with 6 dropouts from the BtA (5\%) groups and two dropouts from the placebo (4\%) groups (Jankovic 2011; Mitsikostas 2018). The reasons for dropping out were not adequately reported in any of the included trials.

The duration of trials ranged from 6 weeks to 20 weeks post-injection. All trials assessed efficacy and other primary outcomes using an intent-to-treat (ITT) analysis, which included all participants randomised to treatment.

\section{Excluded studies}

We listed all the excluded studies in this review, together with reasons for their exclusion, in the Characteristics of excluded studies table.

\section{Risk of bias in included studies}

See Characteristics of included studies: 'Risk of bias' table.

We evaluated the studies using a modified version of the Cochrane 'Risk of bias' tool. See Figure 2 and Figure 3 for the 'Risk of bias' summary graphs. These assessments were based on the information available in the primary report data.

\section{Figure 2. 'Risk of bias' graph: review authors' judgements about each 'Risk of bias' item presented as percentages across all included studies}

Random sequence generation (selection bias)

Allocation concealment (selection bias)

Blinding of participants and personnel (performance bias): All outcomes

Blinding of outcome assessment (detection bias): Objective outcomes

Blinding of outcome assessment (detection bias): Subjective outcomes Incomplete outcome data (attrition bias): All outcomes

Selective reporting (reporting bias)

Enriched population - predominant enrolment of positive responders

Enriched population - exclusion of poor responders

For-profit bias

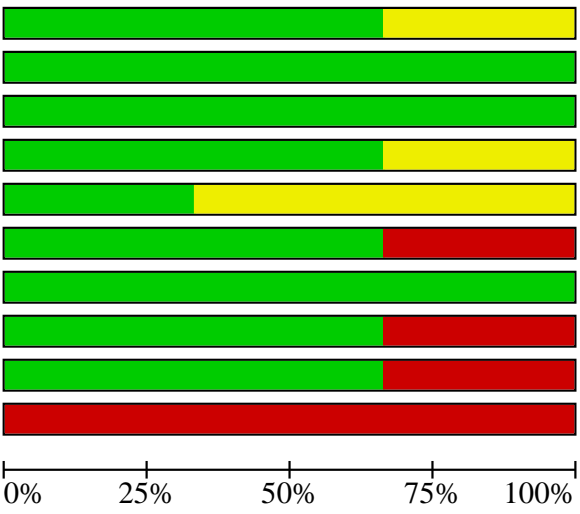


Figure 3. 'Risk of bias' summary: review authors' judgements about each 'Risk of bias' item for each included study

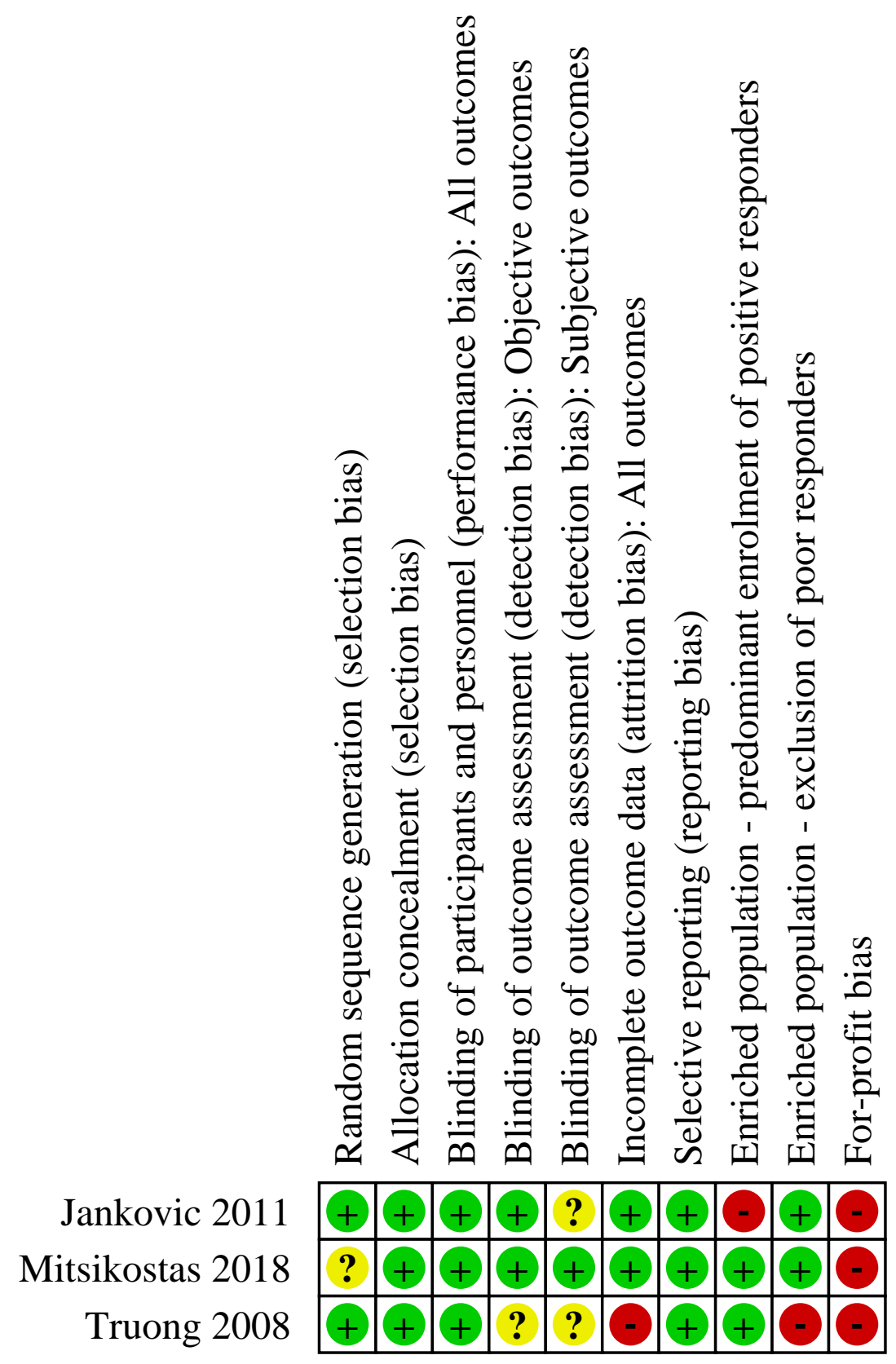

Overall, we considered none of the studies to be at low risk of bias across all domains. All trials were industry-funded, and therefore, we judged them at a high risk of for-profit bias. We assessed Mitsikostas 2018 largely based on the information available in the clinicaltrials.gov web page.

\section{Allocation}

We judged Jankovic 2011 and Truong 2008 to have a low risk of selection bias, as both provided an adequate description of both the randomisation and allocation concealment methods used. Mitsikostas 2018 did not describe the method of randomisation, though we judged allocation concealment to be adequate. 


\section{Blinding}

Overall, we considered there was an unclear risk of performance and detection bias in Jankovic 2011 and Truong 2008, as there was insufficient information to make adequate judgements across multiple domains. We judged Mitsikostas 2018 to be at low risk of bias for both domains.

\section{Incomplete outcome data}

The number of dropouts was low in all groups in Mitsikostas 2018, and unlikely to introduce bias into the study results. The risk of attrition bias was low in Jankovic 2011. Truong 2008 reported a very high proportion of dropouts in the placebo arm (64\%), which may have introduced a relevant bias in the interpretation of the trial results.

\section{Selective reporting}

All trials had a low risk of selective reporting bias.

\section{Other potential sources of bias}

\section{For-profit bias}

All trials were fully funded by pharmaceutical companies, and therefore we judged them at a high risk of for-profit bias.

\section{Enriched population}

Both Jankovic 2011 and Truong 2008 included an enriched population, which may limit the internal reliability of the data, the former predominantly enrolling positive responders to $B t A$, and the latter excluding poor responders to BtA. Mitsikostas 2018 included a treatment-naive population, and we judged it at a low risk of bias in this domain.

\section{Publication bias}

We intended to use funnel plots to explore publication bias. However, due to the small number of included studies, the power of this analysis was considered to be inadequate (Sterne 2011).

\section{Effects of interventions}

See: Summary of findings 1 Botulinum toxin type A compared to placebo for blepharospasm

The key results of this review can be found in 'Summary of findings 1 '.

\section{Primary outcomes}

\section{Blepharospasm-specific improvement}

\subsection{Overall blepharospasm-specific improvement}

Only Jankovic 2011 reported overall blepharospasm-specific improvement, using the total Jankovic Rating Scale (JRS) score.

BtA resulted in a 1.5 point improvement over placebo $(95 \%$ confidence interval (Cl) 0.8 to 2.3 ; 1 trial, 109 participants). We have moderate confidence that BtA may improve overall blepharospasm-specific status.

\subsection{Overall blepharospasm-specific severity improvement}

Treatment with BtA improved blepharospasm-specific severity, as measured with the JRS severity subscore (mean difference (MD)
$0.93,95 \% \mathrm{Cl} 0.61$ to $1.25 ; I^{2}=9 \% ; 3$ trials, 313 participants; moderate-certainty evidence; Analysis 1.1).

\subsection{Overall blepharospasm-specific disability improvement}

Treatment with BtA improved blepharospasm-specific disability, measured with the JRS disability subscore (MD 0.69, 95\% Cl 0.18 to $1.19 ; I^{2}=74 \%$; 3 trials, 313 participants; low-certainty evidence; Analysis 1.2).

\section{Adverse events}

Adverse events related to study treatment were reported in 53\% of BtA-treated participants, compared to $45 \%$ of placebo-treated. Treatment with BtA did not increase the risk of adverse events, when compared with placebo (risk ratio (RR) $1.18,95 \% \mathrm{Cl} 0.87$ to $1.60 ; I^{2}=0 \%$; 2 trials, 169 participants; low-certainty evidence; Analysis 1.3).

Treatment with BtA increased the risk of visual complaints (diplopia, blurred vision, and visual disturbance; RR 5.73, 95\% Cl 1.79 to $18.36 ; I^{2}=52 \% ; 2$ trials, 228 participants; moderate-certainty evidence; Analysis 1.4), and eyelid ptosis (RR $4.02,95 \% \mathrm{Cl} 1.61$ to 10.00; $\left.\right|^{2}=39 \%$; 3 trials, 289 participants; high-certainty evidence; Analysis 1.5).

BtA did not increase the risk of increased lacrimation (RR 2.04, $95 \% \mathrm{Cl} 0.46$ to $9.13 ; \mathrm{I}^{2}=0 \% ; 2$ trials, 228 participants; moderatecertainty evidence; Analysis 1.6) or xerophthalmia (RR $1.83,95 \% \mathrm{Cl}$ 0.69 to $4.86 ; I^{2}=0 \%$; 2 trials, 228 participants; moderate-certainty evidence; Analysis 1.7).

\section{Secondary outcomes}

\section{Subjective evaluation of clinical status}

Two trials contributed data for this outcome (Jankovic 2011; Mitsikostas 2018).

We found a large improvement with BtA compared to placebo (SMD $0.86,95 \% \mathrm{Cl} 0.53$ to $1.20 ; I^{2}=0 \% ; 2$ trials, 170 participants; moderate-certainty evidence; Analysis 1.9).

\section{Frequency of blepharospasm-specific involuntary movements}

Two trials contributed data for this outcome (Jankovic 2011; Truong 2008).

We found a large improvement with BtA compared to placebo (standardised mean difference (SMD) $0.79,95 \% \mathrm{Cl} 0.31$ to $1.27 ; \mathrm{I}^{2}=$ 58\%; 2 trials, 252 participants; low-certainty evidence; Analysis 1.8).

\section{Health-related quality of life}

None of the included trials reported data for this outcome.

\section{Tolerability - dropouts}

Two trials contributed data for this outcome (Jankovic 2011; Mitsikostas 2018.

BtA did not increase the risk of dropouts (RR $1.44,95 \% \mathrm{Cl} 0.31$ to $6.79 ; \mathrm{I}^{2}=0 \%$; 2 trials, 169 participants; moderate-certainty evidence; Analysis 1.10).

\section{Duration of effect}

Only Jankovic 2011 reported this outcome. 
This trial estimated a effect duration of 10.6 weeks (range 6.1 weeks to 19.1 weeks; 1 trial, 109 participants; low-certainty evidence).

\section{DISCUSSION}

\section{Summary of main results}

This updated review included three randomised, parallel-designed trials, that enrolled 313 people with blepharospasm, $61 \%$ of whom had been previously treated with botulinum toxin for their condition.

As can be seen in the Summary of findings 1 , in comparison to placebo, botulinum toxin type A (BtA) improved blepharospasmspecific symptoms. Treatment with BtA also increased the likelihood that participants themselves would detect an improvement. Uncertanity remains over the effect of BtA on people's quality of life, as this outcome was not reported in the included trials.

Treatement with BtA did not increase the risk of experiencing an adverse event, though it did increase the risk of two specific adverse events of special interest - vision complaints (diplopia, blurred vision, and visual disturbance) and eyelid ptosis. No fatalities or serious adverse events were considered to be related to BtA treatment in any trial. Treatment with BtA did not increase the risk of dropouts from the included clinical trials. Data for special subpopulations, such as children and pregnant women, were not available. The duration of response is in accordance with previous observational data.

\section{Overall completeness and applicability of evidence}

All included trials addressed the primary research question directly, using similar and validated assessment tools. However, they did not report data for all outcomes of clinical interest. This limited the amount of data available, and consequently, the confidence in overall conclusions.

The participants included in the trials were not fully representative of the overall population of people with blepharospasm. The effects of population enrichment and the moderate overall impairment (as assessed by the baseline Jankovic Rating Scale (JRS) severity subscores) preclude definite conclusions concerning all people with this condition. The proportion of participants with any adverse event was high in both the BtA and placebo arms. A large nocebo effect, as is common in movement disorders research, may mask safety conclusions (Duarte 2018; Rato 2018; Rato 2019; Silva 2017).

Three noteworthy factors challenge the implementation of the evidence in this review. First, sample size across included trials was relatively small, and subgroup analyses addressing clinically relevant questions for the main outcomes would have been underpowered if conducted. More studies are needed to provide robust evidence for these questions. Second, the use of enriched populations in clinical trials limits applicability of results into clinical practice, as complex and potentially poorer responders are usually excluded from these trials. The fact that such individuals are common in clinical practice further complicates issues of generalisation. Third, it is common for people with blepharospasm to be taking concomitant medications for their condition, such as muscle relaxants and benzodiazepines. Reasonably, participants in trials are required to be on a stable dose of these medications for many weeks to avoid confounding factors. As a result, little is known at present about the impact of these drug regimens with regard to implementation of the evidence in this review.

\section{Quality of the evidence}

See Characteristics of included studies, 'Risk of bias' tables, 'Risk of bias' summary tables (Figure 2; Figure 3), and Summary of findings 1.

We considered all included trials at high risk for for-profit bias, and all but one had an enriched population. We considered all studies to be appropriately blinded in general. However, we considered all but one possibly biased regarding subjective outcome assessment, as all but one predominantly enrolled participants with previous exposure to botulinum toxin. This represents a major methodological limitation that may have resulted in a biased assessment of the intervention effect, particularly with regards to subjective outcomes, which are highly susceptible to biased estimations.

The included trials each enrolled between 61 and 129 participants, and although individually, some of these trials were underpowered, the pooling of the trials permitted an adequate sample size for the efficacy outcomes.

Taken together, as can be seen in Summary of findings 1 , we consider that there is moderate certainty in the evidence that a single treatment session of BtA improves overall blepharospasmspecific severity. There is low certainty in the evidence that the likelihood risk of any adverse event, is low. The certainty in the evidence assessing the change in subjective evaluation of clinical status evaluated by participants is high. We have low certainty that BtA reduced the frequency of blepharospasm-specific involuntary movements. Finally, we have moderate certainty in the evidence that treatment with BtA does not increase the likelihood of participants dropping out of clinical trials.

\section{Potential biases in the review process}

Although we followed the methods recommended by Cochrane in order to minimise bias in the review process, certain areas do deserve attention. In particular, we did not search clinical trials registries. Although this opens the current review to the potential bias of having missed trials, we consider this possibility highly unlikely because we extensively contacted other experts in this field, and USA and European trials in this area are well-known.

\section{Agreements and disagreements with other studies or reviews}

As the previous version of this review was unable to include any trials, the results of this update are novel (Costa 2005). The current clinical practice guidelines of the American Academy of Neurology and the European Academy of Neurology are in agreement that BtA is likely safe and effective for the treatment of blepharospasm (Albanese 2011; Simpson 2016).

\section{AUTHORS' CONCLUSIONS}

\section{Implications for practice}

In this updated Cochrane Review, we found that a single treatment session of botulinum toxin type A (BtA) is effective and welltolerated in the treatment of moderately impaired adults with blepharospasm. The clinical benefit includes moderate to large 
improvements across objective disorder-related domains, such as severity and disability. The benefit is also meaningful when subjectively assessed by the participants.

There is no evidence regarding health-related quality of life. Adverse events are frequent in both BtA (66 of 115 participants) and placebo groups (26 of 54 participants), but are not commonly associated with discontinuing treatment. Vision complaints (49 of 166 BtA-treated participants) and eyelid ptosis (53 of 207 BtA-treated participants) are the most frequent treatment-related adverse events of special interest. We are moderately certain about the conclusions based on the evidence.

\section{Implications for research}

The net benefit of a single BtA injection in the treatment of blepharospasm is likely very positive overall.

Nonetheless, further studies are needed to establish the relative effectiveness of different doses of BtA, assessing efficacy, safety, duration of effect, and quality of life across regimens, with repeated BtA treatment sessions, and assessed under conditions more closely resembling clinical practice (pragmatic clinical trials). Because therapy typically requires optimising a dose for each person, rather than administering a fixed dose of botulinum toxin, such a line of research would be important to support physicians' management of doses, and allow for a more solid and safe individualisation of treatment.
Future research concerning all formulations of botulinum neurotoxin should endeavour to establish clinical effectiveness, not only based on changes from baseline, but also, preferably, based on validated measures of minimal clinically important difference or change (Brożek 2006). Research is required in order to establish such a parameter for the Jankovic Rating Scale (JRS), currently the most widely used and disseminated clinical scale in the field.

It is currently uncertain whether or not the clinical effectiveness of botulinum toxin decays over time, with repeated treatment sessions, and whether a possible loss of effectiveness occurs in all clinical domains. Future studies comparing any form of BtA should address the comparative proportion of participants who develop secondary non-responsiveness to treatment.

Finally, in conducting this systematic review, we were faced with the fact that there is no defined core outcome set in blepharospasm research, as there is for other areas (Tugwell 2007). To promote research in this field, and to support the clinical effectiveness of botulinum toxin, it would be relevant to define a set of core outcome measures, and include it in future research, via well-established methodology, to determine the inclusion of participant-reported outcomes (Macefield 2014).

\section{ACKNOWLEDGEMENTS}

We would like to sincerely thank Ema Roque (Cochrane Movement Disorders) for her editorial support to this review. 


\section{R E F E R E N C E S}

\section{References to studies included in this review}

Jankovic 2011 \{published data only\}

Brodsky M, Jankovic J, Evidente V, Fernandez H, Grafe S. IncobotulinumtoxinA (NT-201) injections are safe and effective in adult subjects with blepharospasm across dosing intervals in a repeated dose-study. Movement Disorders 2011;26(Suppl 2):S206.

Fernandez HH, Evidente VGH, Truong D, Brodsky M, HanschmannA, Comella CL, et al. Long-term treatment of blepharospasm and cervical dystonia: Incobotulinum toxin $A$ is well tolerated when injected at flexible intervals based on patient needs. Journal of the Neurological Sciences 2013;333:e120. [DOI: 10.1016/j.jns.2013.07.403]

Grafe S, Jankovic J, Hanschmann A. Efficacy and safety of NT 201 (botulinum neurotoxin type A free from complexing proteins) for the treatment of blepharospasm: results of a double-blind, placebo-controlled, randomized, multicenter trial. Physical Medicine and Rehabilitation 2010;2:S29-30.

* Jankovic J, Comella C, Hanschmann A, Grafe S. Efficacy and safety of incobotulinumtoxinA (NT 201, Xeomin) in the treatment of blepharospasm - a randomized trial. Movement Disorders 2011;26(8):1521-8. [DOI: 10.1002/mds23658]

Truong DD, Gollomp SM, Jankovic J, LeWitt PA, Marx M, Hanschmann A, Fernandez HH, Xeomin US Blepharospasm Study Group. Sustained efficacy and safety of repeated incobotulinumtoxinA (Xeomin $\left({ }^{\circledR}\right)$ ) injections in blepharospasm. Journal of Neural Transmission 2013;120(9):1345-53. [DOI: 10.1007/s00702-013-0998-9]

\section{Mitsikostas 2018 \{published and unpublished data\}}

Mitsikostas DD, Dekundy A, Sternberg K, Pagan F. Safety and efficacy of incobotulinum toxin A for the treatment of blepharospasm in botulinum toxin-naive subjects. Neurology 2018;90(Suppl 15):P5.041.

NCT01896895. Efficacy and Safety Study of Botulinum Toxin Type A Against Placebo to Treat Abnormal Contraction or Twitch of the Eyelid [Prospective, Double-blind, Placebo-controlled, Randomized, Parallel-group, Multi-center Study With an Openlabel Extension Period to Investigate the Efficacy and Safety of Two Different Doses of NT 201 in Botulinum Toxin Treatmentnaïve Subjects With Blepharospasm]. clinicaltrials.gov/show/ NCT01896895 (first received 11 Jully 2013).

\section{Truong 2008 \{published data only\}}

* Truong D, Comella C, Fernandez HH, Ondo WG, Dysport Benign Essential Blepharospasm Study Group. Efficacy and safety of purified botulinum toxin type A (Dysport) for the treatment of benign essential blepharospasm: a randomized, placebo-controlled, phase II trial. Parkinsonism and Related Disorders 2008;14(5):407-14. [10.1016/j.parkreldis.2007.11.003]

\section{References to studies excluded from this review}

Aramideh 1995 \{published data only\}

* Aramideh M, Ongerboer de Visser BW, Brans JW, Koelman JH, Speelman JD. Pretarsal application of botulinum toxin for treatment of blepharospasm. Journal of Neurology, Neurosurgery and Psychiatry 1995;59(3):309-11.

\section{Boyle 2009 \{published data only\}}

Boyle M, McGwin M, Flanagan C, Vicinanzo M, Long J. High versus low concentration botulinum toxin $A$ for benign essential blepharospasm: does dilution make a difference? Ophthalmic Plastic and Reconstructive Surgery 2009;25(2):81-4.

Fahn 1985 \{published data only\}

* Fahn S, List T, Moslowitz C, Brin M, Bressman S, Burke R, Scott A. Double-blind controlled study of botulinum toxin for blepharospasm. Neurology 1985;35(Suppl 1):271-2.

Frueh 1988 \{published data only\}

* Frueh BR, Nelson CC, Kapustiak JF, Mush DC. The effect of omitting botulinum toxin from the lower eyelid in blepharospasm treatment. American Journal of Ophthalmology 1988;106:45-7.

Girlanda 1996 \{published data only\}

* Girlanda P, Quartarone A, Sinicropi S, Nicolosi C, Messina C. Unilateral injection of botulinum toxin in blepharospasm: single fiber electromyography and blink reflex study. Movement Disorders 1996;11(1):27-31.

Iwashige 1995 \{published data only\}

* Iwashige H, Nemoto Y, Takahashi H, Maruo T. Botulinum toxin type A (Botox) for treatment of blepharospasm: an open label, dose response study. Nihon Ganka Gakkai Zasshi 1995;99(6):663-8.

Jankovic 1987 \{published data only\}

* Jankovic J, Orman J. Botulinum A toxin for cranial-cervical dystonia: a double-blind, placebo-controlled study. Neurology 1987;37:616-23.

Jankovic J. Blepharospasm and oromandibular-laryngeal cervical dystonia: a controlled trial of botulinum A toxin therapy. Advances in Neurology 1988;50:583-591.

Jankovic 1995 \{published data only\}

* Jankovic J. Apraxia of lid opening. Movement Disorders 1995;10(5):686-7.

Jankovic J. Pretarsal injection of botulinum toxin for blepharospasm and apraxia of eyelid opening. Journal of Neurology, Neurosurgery and Psychiatry 1996;60(6):704.

Mezaki 1995 \{published data only\}

* Mezaki T, Kaji R, Kohara N, Fujii H, Katayama M, Shimizu T, et al. Comparison of therapeutic efficacies of type $A$ and $F$ botulinum toxins for blepharospasm: a double-blind, controlled study. Neurology 1995;45(3 Pt 1):506-8. 
Mezaki 1999 \{published data only\}

* Mezaki T, Kaji R, Brin MF, Hirota-Katayama M, Kubori T, Shimizu T, et al. Combined use of type $A$ and $F$ botulinum toxins for blepharospasm: a double-blind controlled trial. Movement Disorders 1999;14(6):1017-20.

\section{Nussgens 1997 \{published data only\}}

* Nussgens Z, Roggenkamper P. Comparison of two botulinumtoxin preparations in the treatment of essential blepharospasm. Graefes Archives of Clinical and Experimental Ophthalmology 1997;235(4):197-9.

Pagan 2018 \{unpublished data only\}

Park 1993 \{published data only\}

* Park YC, Lim JK, Lee DK, Doe Yi S. Botulinum A toxin treatment of hemifacial spasm and blepharospasm. Journal of Korean Medical Science 1993;8(5):334-40.

\section{Price 1997 \{published data only\}}

* Price J, Farish S, Taylor H, O'Day J. Blepharospasm and hemifacial spasm. Randomized trial to determine the most appropriate location for botulinum toxin injections. Ophthalmology 1997;104(5):865-8.

\section{Sampaio 1997 \{published data only\}}

Sampaio C, Ferreira JJ, Simões F, Rosas MJ, Magalhães M, Martins R, et al. DYSBOT: a single blind, randomized clinical trial to compare two different formulations of botulinum toxin type A. Movement Disorders 1995;10(3):387.

* Sampaio C, Ferreira JJ, Simoes F, Rosas MJ, Magalhaes M, Correia AP, et al. DYSBOT: a single-blind, randomized parallel study to determine whether any differences can be detected in the efficacy and tolerability of two formulations of botulinum toxin type A - Dysport and Botox - assuming a ratio of 4:1. Movement Disorders 1997;12(6):1013-8.

\section{Additional references}

\section{Abrams 2005}

Abrams KR, Gillies CL, Lambert PC. Meta-analysis of heterogeneously reported trials assessing change from baseline. Statistics in Medicine 2005;24:3823-44.

\section{Albanese 2011}

Albanese A, Asmus F, Bhatia KP, Elia AE, Elibol B, Filippini G, et al. EFNS guidelines on diagnosis and treatment of primary dystonias. European Journal of Neurology 2011;18:5-18.

\section{Albanese 2013}

Albanese A, Bhatia K, Bressman SB, Delong MR, Fahn S, Fung VS, et al. Phenomenology and classification of dystonia: a consensus update. Movement Disorders 2013;28(7):863-73.

\section{Altman 2002}

Altman DG, Deeks JJ. Meta-analysis, Simpson's paradox, and the number needed to treat. BMC Medical Research Methodology 2002;2:3.

\section{Antonucci 2008}

Antonucci F, Rossi C, Gianfranceschi L, Rossetto O, Caleo M. Long-distance retrograde effects of botulinum neurotoxin. Journal of Neuroscience 2008;28:3689-96.

\section{Aramideh 1994}

Aramideh M, Ongerboer de Visser BW, Devriese PP, Bour LJ, Speelman JD. Electromyographic features of levator palpebrae superioris and orbicularis oculi muscles in blepharospasm. Brain 1994;117:27-38.

\section{Balshem 2011}

Balshem H, Helfand M, Schünemann HJ, Oxman AD, Kunz R, Brozek J, et al. GRADE guidelines: 3 . Rating the quality of evidence. Journal of Clinical Epidemiology 2011;64(4):401-6.

\section{Berardelli 1985}

Berardelli A, Rothwell JC, Day BL, Maesden CD. Pathophysiology of blepharospasm and oromandibular dystonia. Brain 1985;108:593-608.

\section{Boroff 1975}

Boroff DA, Chen GS. On the question of permeability of the blood-brain barrier to botulinum toxin. International Archives of Allergy and Applied Immunology 1975;48:495-504.

\section{Brożek 2006}

Brożek JL, Guyatt GH, Schünemann HJ. How a well-grounded minimal important difference can enhance transparency of labelling claims and improve interpretation of a patient reported outcome measure. Health and Quality of Life Outcomes 2006;4:69.

\section{Cardoso 1995}

Cardoso F, Jankovic J. Blepharospasm. In: Handbook of Dystonia. Tsui J, Calne D edition. New York: Marcel Dekker, 1995:129-42.

\section{Carpenter 2013}

Carpenter J, Kenward M. Multiple Imputation and its Application. 1st edition. John Wiley \& Sons, 2013.

\section{Carrasco-Labra 2016}

Carrasco-Labra A, Brignardello-Petersen R, Santesso N, Neumann I, Mustafa RA, Mbuagbaw L, et al. Improving GRADE evidence tables part 1: a randomized trial shows improved understanding of content in summary of findings tables with a new format. Journal of clinical epidemiology 2016;74:7-18. [PMID: 26791430]

\section{Castelão 2017}

Castelão M, Marques RE, Duarte GS, Rodrigues FB, Ferreira J, Sampaio C, et al. Botulinum toxin type A therapy for cervical dystonia. Cochrane Database of Systematic Reviews 2017, Issue 12. Art. No: CD003633. [DOI: 10.1002/14651858.CD003633.pub3]

\section{Cohen 1988}

Cohen J. Statistical Power Analysis in the Behavioral Sciences. 2nd edition. Hillsdale (NJ): Lawrence Erlbaum Associates, Inc., 1988. 


\section{Corbett 2014}

Corbett MS, Higgins JP, Woolacott NF. Assessing baseline imbalance in randomised trials: implications for the Cochrane risk of bias tool. Research Synthesis Methods 2014;5(1):79-85.

\section{Costa 2005a}

Costa J, Espírito-Santo CC, Borges AA, Ferreira J, Coelho MM, Moore $P$, et al. Botulinum toxin type A therapy for hemifacial spasm. Cochrane Database of Systematic Reviews 2005;(1).

\section{de Paiva 1999}

de Paiva A, Meunier FA, Molgó J, Aoki KR, Dolly JO. Functional repair of motor endplates after botulinum neurotoxin type A poisoning: biphasic switch of synaptic activity between nerve sprouts and their parent terminals. Proceedings of the National Academy of Sciences of the United States of America 1999;96:3200-5.

\section{Deeks 2011}

Deeks JJ, Higgins JPT, Altman DG, editor(s). Chapter 9: Analysing data and undertaking meta-analyses. In: Higgins JPT, Green S, editor(s). Cochrane Handbook for Systematic Reviews of Interventions Version 5.1.0 (updated March 2011). The Cochrane Collaboration, 2011. Available at www.training.cochrane.org/handbook.

\section{Duarte 2016}

Duarte GS, Castelão M, Rodrigues FB, Marques RE, Ferreira J, Sampaio $C$, et al. Botulinum toxin type $A$ versus botulinum toxin type B for cervical dystonia. Cochrane Database of Systematic Reviews 2016, Issue 10. Art. No: CD004314. [DOI: 10.1002/14651858.CD004314.pub3]

\section{Duarte 2018}

Duarte GD, Rodrigues FB, Ferreira JJ, Costa J. Adverse events with botulinum toxin treatment in cervical dystonia: how much should we blame placebo? Parkinsonism \& Related Disorders 2018;56:16-9. [DOI: 10.1016/j.parkreldis.2018.06.017]

\section{Duchen 1971}

Duchen LW. An electron microscopic study of the changes induced by botulinum toxin in the motor end-plates of slow and fast skeletal muscle fibres of the mouse. Journal of the Neurological Sciences 1971;14(1):47-60.

\section{Elston 1988}

Elston JS, Marsden CD, Grandas F, Quinn NT. The significance of ophthalmological symptoms in idiopathic blepharospasm. Eye 1988;2:435-9.

\section{Filippi 1993}

Filippi GM, Errico P, Santarelli R, Bagolini B, Manni E. Botulinum $A$ toxin effects on rat jaw muscle spindles. Acta Otolaryngologica 1993;113:400-4.

\section{Follmann 1992}

Follmann D, Elliott P, Suh I, Cutler J. Variance imputation for overviews of clinical trials with continuous response. Journal of Clinical Epidemiology 1992;45:769-73.

\section{Frevert 2010}

Frevert J, Dressler D. Complexing proteins in botulinum toxin type A drugs: a help or a hindrance? Biologics: Targets \& Therapy 2010 Dec;4:325-32.

\section{Frueh 1976}

Frueh BR, Callahan A, Dortzbach RK, Wilkins RB, Beale HL, Reitman HS, et al. A profile of patients with intractable blepharospasm. Transactions of the American Academy of Ophthalmology and Otolaryngology 1976;81(4 Pt 1):OP591-4.

\section{Furukawa 2006}

Furukawa TA, Barbui C, Cipriani A, Brambilla P, Watanabe N. Imputing missing standard deviations in meta-analyses can provide accurate results. Journal of Clinical Epidemiology 2006;59(1):7-10.

\section{GRADEpro GDT [Computer program]}

McMaster University (developed by Evidence Prime) GRADEpro GDT. Version accessed 3 January 2017. Hamilton (ON): McMaster University (developed by Evidence Prime). Available at gradepro.org.

\section{Grandas 1988}

Grandas F, Elston J, Quinn N, Marsden CD. Blepharospasm: a review of 264 patients. Journal of Neurology, Neurosurgery and Psychiatry 1988;51:767-72.

\section{Grandas 1998}

Grandas F, Traba A, Alonso F, Esteban A. Blink reflex recovery cycle in patients with blepharospasm unilaterally treated with botulinum toxin. Clinical Neuropharmacology 1998;21(5):307-11.

\section{Guyatt 2011}

Guyatt GH, Oxman AD, Kunz R, Brozek J, Alonso-Coello P, Rind $D$, et al. GRADE guidelines 6 . Rating the quality of evidence-imprecision. Journal of Clinical Epidemiology 2011;64(12):1283-93.

\section{Hedges 1985}

Hedges LV, Olkin I. Statistical Methods for Meta-Analysis. San Diego, California: Academic Press, Inc, 1985.

\section{Henderson 1956}

Henderson JW. Essential blepharospasm. Transactions of the American Academy of Ophthalmology Society 1956;54:453-520.

\section{Higgins 2003 \\ Higgins JPT, Thompson SG, Deeks JJ, Altman DG. Measuring inconsistency in meta-analyses. BMJ 2003;327(7414):557-60.}

\section{Higgins 2011a}

Higgins JPT, Altman DG, Sterne JAC, editor(s). Chapter 8: Assessing risk of bias in included studies. In: Higgins JPT, Green S, editor(s). Cochrane Handbook for Systematic Reviews of Interventions Version 5.1.0 (updated March 2011). The Cochrane Collaboration, 2011. Available at www.training.cochrane.org/ handbook. 


\section{Higgins 2011b}

Higgins JPT, Deeks JJ, Altman DG, editor(s). Chapter 16: Special topics in statistics. In: Higgins JPT, Green S, editor(s), Cochrane Handbook for Systematic Reviews of Interventions Version 5.1.0 (updated March 2011). The Cochrane Collaboration, 2011. Available at www.training.cochrane.org/handbook.

\section{Higgins 2011c}

Higgins JPT, Deeks JJ, editor(s). Chapter 7: Selecting studies and collecting data. In: Higgins JPT, Green S, editor(s), Cochrane Handbook for Systematic Reviews of Interventions Version 5.1.0 (updated March 2011). The Cochrane Collaboration, 2011. Available at www.training.cochrane.org/handbook.

\section{Holland 1981}

Holland RL, Brown MC. Nerve growth in botulinum toxin poisoned muscles. Neuroscience 1981;6:1167-79.

\section{Jankovic 1982a}

Jankovic J. Treatment of hyperkinetic movement disorders with tetrabenazine: a double blind crossover study. Annals of Neurology 1982;11:41-7.

\section{Jankovic 1982b}

Jankovic J, Havins WE, Wilkins RB. Blinking and blepharospasm Journal of the American Medical Association 1982;248:3160-4.

\section{Jankovic 1983}

Jankovic J, Ford J. Blepharospasm and orofacial-cervical dystonia: clinical and pharmacology findings in 100 patients. Annals of Neurology 1983;13:402-11.

\section{Jankovic 2004}

Jankovic J. Botulinum toxin in clinical practice. Journal of Neurology, Neurosurgery, and Psychiatry 2004;75(7):951-7.

\section{Juzans 1996}

Juzans P, Comella J, Molgo J, Faille L, Angaut-Petit D. Nerve terminal sprouting inbotulinum type-A treated mouse levator auris longus muscle. Neuromuscular Disorders: NMD 1996;6(3):177-85.

\section{Liberati 2009}

Liberati A, Altman DG, Tetzlaff J, Mulrow C, Gøtzsche PC, Ioannidis JP, et al. The PRISMA statement for reporting systematic reviews and meta-analyses of studies that evaluate health care interventions: explanation and elaboration. PLOS Medicine 2009;6:e1000100.

\section{Macefield 2014}

Macefield RC, Jacobs M, Korfage IJ, Nicklin J, Whistance RN, Brookes ST, et al. Developing core outcomes sets: methods for identifying and including patient-reported outcomes (PROs). Trials 2014;15:49.

\section{Marques 2016}

Marques RE, Duarte GS, Rodrigues FB, Castelão M, Ferreira J, Sampaio $C$ et al. Botulinum toxin type B for cervical dystonia. Cochrane Database of Systematic Reviews 2016, Issue 5. Art. No: CD004315. [DOI: 10.1002/14651858.CD004315.pub3] [PMID: 27176573]

\section{Marsden 1976}

Marsden CD. Blepharospasm-oromandimular dystonia syndrome. Journal of Neurology, Neurosurgery and Psychiatry 1976;390:1204-9.

\section{Matak 2014}

Matak I, Lacković Z. Botulinum toxin A, brain and pain. Progress in Neurobiology 2014 Aug-Sep;119-120:39-59.

\section{Matak 2015}

Matak I, Lacković Z. Botulinum neurotoxin type A: actions beyond SNAP-25? Toxicology 2015;335:79-84.

\section{Nutt 1988}

Nutt JG, Muenter MD, Melton LJ 3rd, Aronson A, Kurland LT. Epidemiology of focal and generalized dystonia in Rochester, Minnesota. Movement Disorders 1988;3(3):188-94.

\section{Palomar 2012}

Palomar FJ, Mir P. Neurophysiological changes after intramuscular injection of botulinum toxin. Clinical Neurophysiology 2012;123:23:54-60.

\section{Pellizzari 1999}

Pellizzari R, Rossetto O, Schiavo G, Montecucco C. Tetanus and botulinum neurotoxins: mechanism of action and therapeutic uses. Philosophical Transactions of the Royal Society of London. Series B, Biological Sciences 1999;354:259-68.

\section{Peters 2006}

Peters JL, Sutton AJ, Jones DR, Abrams KR, Rushton L. Comparison of two methods to detect publication bias in meta-analysis. Journal of the American Medical Association 2006;295(6):676-80.

\section{Rato 2018}

Rato ML, Duarte GS, Mestre T, de Carvalho M, Ferreira JJ. Strong nocebo effect in amyotrophic lateral sclerosis trials might mask conclusions. Lancet Neurology 2018;17(10):842. [DOI: 10.1016/ S1474-4422(18)30310-7]

\section{Rato 2019}

Rato ML, Duarte GS, Ferreira AN, Alves M, Mainoli B, Teodoro T, et al. Nocebo response in Parkinson's disease: a systematic review and meta-analysis. Parkinsonism \& Related Disorders 2019;65:13-9. [DOI: 10.1016/j.parkreldis.2019.04.015]

\section{Review Manager 2014 [Computer program]}

Nordic Centre, The Cochrane Collaboration Review Manager 5 (RevMan 5). Version 5.3. Copenhagen: Nordic Centre, The Cochrane Collaboration, 2014.

\section{Rosales 1996}

Rosales RL, Arimura K, Takenaka S, Osame M. Extrafusal and intrafusal muscle effects in experimental botulinum toxin- $A$ injection. Muscle \& Nerve 1996;19:488-96.

\section{Rosales 2010}

Rosales RL, Dressler D. On muscle spindles, dystonia and botulinum toxin. European Journal of Neurology 2010;17:71-80. 


\section{Rubin 1991}

Rubin DB, Schenker N. Multiple imputation in health-care databases: an overview and some applications. Statistics in Medicine 1991;10:585-98.

\section{Schünemann 2011}

Schünemann HJ, Oxman AD, Higgins JPT, Vist GE, Glasziou P, Guyatt GH. Chapter 11: Presenting results and 'Summary of findings' tables. In: Higgins JPT, Green S, editor(s), Cochrane Handbook for Systematic Reviews of Interventions Version 5.1.0 (updated March 2011). The Cochrane Collaboration, 2011. Available at www.training.cochrane.org/handbook.

\section{Silva 2017}

Silva MA, Duarte GS, Camara R, Rodrigues FB, Fernandes RM, Abreu $\mathrm{D}$, et al. Placebo and nocebo responses in restless legs syndrome: a systematic review and meta-analysis. Neurology 2017;88(23):2216-24. [DOI: 10.1212/WNL.0000000000004004]

\section{Simpson 2004}

Simpson LL. Identification of the major steps in botulinum toxin action. Annual Review of Pharmacology and Toxicology 2004;44:167-93.

\section{Simpson 2016}

Simpson DM, Hallett M, Ashman EJ, Comella CL, Green MW, Gronseth GS, et al. Practice guideline update summary: botulinum neurotoxin for the treatment of blepharospasm, cervical dystonia, adult spasticity, and headache: report of the Guideline Development Subcommittee of the American Academy of Neurology. Neurology 2016;10:1818-26.

\section{Smeeth 1999}

Smeeth L, Haines A, Ebrahim S. Numbers needed to treat derived from meta-analysis - sometimes informative, usually misleading. BMJ 1999;318(7197):1548-51.

\section{Stata [Computer program]}

Stata. Version 15. College Station, TX, USA: StataCorp., 2017. Available from www.stata.com

\section{Steeves 2012}

Steeves TD, Day L, Dykeman J, Jette N, Pringsheim T. The prevalence of primary dystonia: a systematic review and metaanalysis. Movement Disorders 2012;27(14):1789-96.

\section{Sterne 2001}

Sterne JA, Egger M. Funnel plots for detecting bias in metaanalysis: guidelines on choice of axis. Journal of Clinical Epidemiology 2001;54(10):1046-55.

\section{Sterne 2011}

Sterne JAC, Egger M, Moher D, editor(s). Chapter 10: Addressing reporting biases. In: Higgins JPT, Green S, editor(s). Cochrane Handbook for Systematic Reviews of Intervention. Version 5.1.0 (updated March 2011). The Cochrane Collaboration, 2011. Available at www.training.cochrane.org/handbook 2011.

\section{Tarsy 2006}

Tarsy D, Simon DK. Dystonia. New England Journal of Medicine 2006;355:818-29.

\section{Thorlund 2011}

Thorlund K, Engstrøm J, Wetterslev J, Brok J, Imberger G, Gluud C. User manual for Trial Sequential Analysis (TSA). ctu.dk/ tsa/files/tsa manual.pdf 2011.

\section{Tolosa 1979}

Tolosa ES, Klawans HL. Meige's disease: a clinical form of a facial convulsion, bilateral and medial. Archives of Neurology 1979;36:635-7.

\section{Tolosa 1981}

Tolosa ES. Clinical features of Meige's disease (idiopathic orofacial dystonia): a report of 17 cases. Archives of Neurology 1981;36:147-51.

\section{Tolosa 1988}

Tolosa E, Marti MJ. Blepharospasm-oromandibular dystonia syndrome (Meige's syndrome): clinical aspects. Advances in Neurology 1988:73-84.

\section{TSA 2011 [Computer program]}

Copenhagen Trial Unit Trial Sequential Analysis. Version 0.9 Beta. Copenhagen Trial Unit, Version accessed 3 January 2017. Copenhagen: Copenhagen Trial Unit, 2011. Available at www.ctu.dk/tsa/downloads.aspx.

\section{Tucha 2001}

Tucha O, Naumann M, Berg D, Alders GL, Lange KW. Quality of life in patients with blepharospasm. Acta Neurologica Scandinavica 2001;103(1):49-52.

\section{Tugwell 2007}

Tugwell P, Boers M, Brooks P, Simon L, Strand V, Idzerda L. OMERACT: an international initiative to improve outcome measurement in rheumatology. Trials 2007;8:38.

\section{Walker 2014}

Walker TJ, Dayan SH. Comparison and overview of currently available neurotoxins. Journal of Clinical and Aesthetic Dermatology 2014;7(2):31-9.

\section{Wiebe 2006}

Wiebe N, Vandermeer B, Platt RW, Klassen TP, Moher D, Barrowman NJ. A systematic review identifies a lack of standardization in methods for handling missing variance data. Journal of Clinical Epidemiology 2006;59(4):342-53.

\section{Zoons 2012}

Zoons E, Dijkgraaf MGW, Dijk JM, vVan Schaik IN, Tijssen MA. Botulinum toxin as treatment for focal dystonia: a systematic review of the pharmaco-therapeutic and pharmaco-economic value. Neurology 2012;259(12):2519-26.

\section{References to other published versions of this review}

\section{Costa 2005}

Costa J, Espírito-Santo C, Borges A, Ferreira JJ, Coelho M, Moore $P$, et al. Botulinum toxin type A therapy for blepharospasm. Cochrane Database of Systematic 
Reviews 2005, Issue 2. Art. No: CD004900. [DOI:

10.1002/14651858.CD004900.pub2]

CHARACTERISTICS OF STUDIES

Characteristics of included studies [ordered by study ID]

Jankovic 2011

\section{Study characteristics}

Methods

Randomised, double-blind, parallel design

Randomisation: carried out in blocks of four; RANCODE

Setting: multicentre

Duration: 20 weeks
* Indicates the major publication for the study

129 participants enrolled (BtA group $=75 ;$ placebo group $=34$ )

$\%$ Female: BtA: 65\%; placebo: $65 \%$

Mean age (range): BtA: 61.5 years (SD 11); placebo: 62.6 years (SD 8.7)

Mean blepharospasm duration: BtA: 233.2 months; placebo: 278 months

Mean blepharospasm severity (SD) using JRS total score: BtA: 5.87 (1.49); placebo: 5.76 (1.23)

Inclusion criteria:

- 18 years to 80 years of age

- blepharospasm diagnosis, with a minimum JRS severity subscore $\geq 2$

- stable satisfactory therapeutic response directly prior to trial entry

\section{Exclusion criteria:}

- atypical variant of benign essential blepharospasm caused by inhibition of levator palpebrae muscle

- myotomy or denervation surgery in the affected muscles (e.g. peripheral denervation and/or spinal cord stimulation)

- previous two injections with BtA with more than 50 units per eye

- treatment with BtA for any indication other than benign essential blepharospasm within 4 months prior to baseline assessment and during the trial

- medical conditions or treatments known to be contraindicated for the injection of onabotulinumtoxinA

Interventions

BtA dose, dilution, volume, and injection site were selected based on the last 2 BtA treatments $( \pm 10 \%)$ prior to the start of the study, up to a maximum of 50 units per eye. Each participant received only one treatment in each eye.

BtA: Xeomin (incobotulinumtoxinA); vials were reconstituted with $0.9 \%$ sodium chloride up to 50 units per eye

Placebo: matching

Study drug preparation: BtA provided in vials by Merz

EMG guidance: no

Outcomes

Primary outcome:

- Jankovic Rating Scale severity subscore

Secondary outcomes: 
- Blepharospasm Disability Index

- participant evaluation of global response at final visit

- global assessment of efficacy and tolerability at the end of the trial using a 4-point Likert scale ranging from 1 to 4

- time from injection to onset of treatment effect

- time to waning of treatment effect based on participants' subjective assessments

- time from injection to re-treatment (the difference between treatment effect onset and treatment effect waning)

Notes

Merz Pharmaceuticals GmbH (Frankfurt, Germany) was responsible for the funding, conduct, data collection, and statistical analysis of the study. Authors had full access to all study data.

\section{Risk of bias}

\begin{tabular}{lll}
\hline Bias & Authors' judgement & Support for judgement \\
\hline $\begin{array}{l}\text { Random sequence genera- } \\
\text { tion (selection bias) }\end{array}$ & Low risk & $\begin{array}{l}\text { 'Patients were randomised by personnel not involved in other study proce- } \\
\text { dures (...) using RANCODE version 3.6 (IDV, Gauting, Germany) for blockwise } \\
\text { randomization (...), ensuring stratification by center.' }\end{array}$ \\
\hline $\begin{array}{l}\text { Allocation concealment } \\
\text { (selection bias) }\end{array}$ & Low risk & Comment: method of concealment not specified \\
\hline $\begin{array}{l}\text { Blinding of participants } \\
\begin{array}{l}\text { and personnel (perfor- } \\
\text { mance bias) }\end{array}\end{array}$ & Low risk & \\
All outcomes & $\begin{array}{l}\text { 'Investigators and patients were blinded to the treatment assignment: place- } \\
\text { bo and incobotulinumtoxinA vials had the same appearance, and neither the } \\
\text { investigator nor other medical staff or any subject knew the identity of individ- } \\
\text { ual study medication.' }\end{array}$
\end{tabular}

\begin{tabular}{|c|c|c|}
\hline $\begin{array}{l}\text { Blinding of outcome as- } \\
\text { sessment (detection bias) } \\
\text { Objective outcomes }\end{array}$ & Low risk & $\begin{array}{l}\text { 'JRS (both subscores) and the BSDI assessments were performed at each visit } \\
\text { by the same blinded, independent rater, who was not involved in any other tri- } \\
\text { al procedure.' }\end{array}$ \\
\hline
\end{tabular}

\begin{tabular}{|c|c|c|}
\hline \multirow{3}{*}{$\begin{array}{l}\text { Blinding of outcome as- } \\
\text { sessment (detection bias) } \\
\text { Subjective outcomes }\end{array}$} & Unclear risk & $\begin{array}{l}\text { 'A second investigator was responsible for all other assessments and proce- } \\
\text { dures during the course of the trial.' }\end{array}$ \\
\hline & & Comment: Investigator blinding not specified. \\
\hline & & $\begin{array}{l}\text { Although placebo was identical to intervention, the fact that all of the partici- } \\
\text { pants were previously treated with botulinum toxin could have led to a degree } \\
\text { of bias. }\end{array}$ \\
\hline
\end{tabular}

\begin{tabular}{|c|c|c|}
\hline $\begin{array}{l}\text { Incomplete outcome data } \\
\text { (attrition bias) } \\
\text { All outcomes }\end{array}$ & Low risk & $\begin{array}{l}\text { Comment: post-randomisation exclusions were low and roughly distributed } \\
\text { evenly between groups (BtA group }=5 / 75 \text {; Placebo group }=2 / 34) \text {. The reasons } \\
\text { are described and 'no patient discontinued prematurely because of adverse } \\
\text { events or insufficient efficacy'. }\end{array}$ \\
\hline
\end{tabular}

\begin{tabular}{|c|c|c|}
\hline $\begin{array}{l}\text { Selective reporting (re- } \\
\text { porting bias) }\end{array}$ & Low risk & $\begin{array}{l}\text { 'Efficacy was analyzed using the full analysis set (FAS) population, which in- } \\
\text { cluded all randomised patients.' }\end{array}$ \\
\hline
\end{tabular}
'All patients who received the trial medication were included in the descriptive safety analysis.'
Comment:
The outcomes mentioned in the study protocol matched the outcomes report- ed in the study.


Jankovic 2011 (Continued)

Enriched population - pre- High risk Enriched population due to exclusive enrolment of people responsive to previdominant enrolment of ous botulinum toxin treatment.

positive responders

'A documented stable therapeutic response to the last 2 consecutive injections with onabotulinumtoxinA.'

Enriched population - ex- Low risk Exclusion of people known to have poorer response to treatment, such as eyeclusion of poor responders lid ataxia.

For-profit bias High risk Comment: study funded by Merz Pharmaceuticals GmbH

Mitsikostas 2018

\section{Study characteristics}

Methods

Randomised, double-blind

Randomisation: no information

Setting: multicentre

Duration: 6 weeks

\section{Participants}

61 participants enrolled (BtA group $=61 ;$ placebo group $=20)$

Female: BtA 59\%; placebo 60\%

Mean age (SD): BtA: 54.6 years (14.2); placebo: 55.4 years (12)

Mean blepharospasm duration: no information

Mean blepharospasm severity (SD) using JRS total score: no information

\section{Inclusion criteria:}

- age $\geq 18$ and $\leq 80$ years

- diagnosis of bilateral blepharospasm

- JRS severity subscore $\geq 2$

- treatment-naïve subject defined as at least 12 months without Botox of any serotype for the treatment of blepharospasm

\section{Exclusion criteria:}

- subject with any previous unsuccessful treatment with Botox of any serotype for the treatment of blepharospasm

- atypical variant of blepharospasm (e.g. apraxia of the eyelid opening) caused by inhibition of levator palpebrae muscle

- neuroleptic-induced blepharospasm

- myotomy or denervation surgery in the affected muscles (e.g. peripheral denervation, spinal cord stimulation) and surgery in the upper face

- generalised disorders of muscles activity (e.g. myasthenia gravis in particular ocularis, Lambert-Eaton Syndrome, amyotrophic lateral sclerosis) or any other significant neuromuscular dysfunction, which might interfere with the study

Interventions

BtA: Xeomin (incobotulinumtoxinA)

Placebo: $1.0 \mathrm{~mL}$ placebo matched to the volume of BtA doses per injection session via intramuscular injections into orbicular oculi muscles 
Mitsikostas 2018 (Continued)

Study drug preparation: participants received $1.0 \mathrm{~mL}$ of incobotulinumtoxinA containing 25 units or 50 units per injection session ( 12.5 units or 25 units per eye) via intramuscular injections into orbicular oculi muscles

\section{EMG guidance: no}

\begin{tabular}{ll}
\hline Outcomes & Primary outcome: \\
- Jankovic Rating Scale severity subscore \\
Secondary outcomes: \\
- Blepharospasm Disability Index \\
- Participant evaluation of global response at final visit \\
- adverse events
\end{tabular}

Notes Merz Pharmaceuticals GmbH (Frankfurt, Germany) funded this trial

\section{Risk of bias}

\begin{tabular}{|c|c|c|}
\hline Bias & Authors' judgement & Support for judgement \\
\hline $\begin{array}{l}\text { Random sequence genera- } \\
\text { tion (selection bias) }\end{array}$ & Unclear risk & Comment: method of randomisation not specified \\
\hline $\begin{array}{l}\text { Allocation concealment } \\
\text { (selection bias) }\end{array}$ & Low risk & Comment: method of concealment adequate given central allocation \\
\hline $\begin{array}{l}\text { Blinding of participants } \\
\text { and personnel (perfor- } \\
\text { mance bias) } \\
\text { All outcomes }\end{array}$ & Low risk & Comment: adequate method of blinding \\
\hline $\begin{array}{l}\text { Blinding of outcome as- } \\
\text { sessment (detection bias) } \\
\text { Objective outcomes }\end{array}$ & Low risk & Comment: adequate method of blinding \\
\hline $\begin{array}{l}\text { Blinding of outcome as- } \\
\text { sessment (detection bias) } \\
\text { Subjective outcomes }\end{array}$ & Low risk & Comment: adequate method of blinding \\
\hline $\begin{array}{l}\text { Incomplete outcome data } \\
\text { (attrition bias) } \\
\text { All outcomes }\end{array}$ & Low risk & $\begin{array}{l}\text { Comment: low participant dropouts, though unlikely to introduce bias in the } \\
\text { results }\end{array}$ \\
\hline $\begin{array}{l}\text { Selective reporting (re- } \\
\text { porting bias) }\end{array}$ & Low risk & Comment: all outcomes available \\
\hline
\end{tabular}

Enriched population - pre- Low risk Comment: treatment-naive population dominant enrolment of positive responders

\begin{tabular}{l}
$\begin{array}{l}\text { Enriched population - ex- } \\
\text { clusion of poor responders }\end{array}$ \\
\hline
\end{tabular}

For-profit bias High risk Comment: study funded by Merz Pharmaceuticals GmbH.




\section{Study characteristics}

Methods
Randomised, double-blind, placebo-controlled

Randomisation: participants were allocated sequential numbers and randomly assigned to one of the four treatment groups according to a computer-generated randomisation schedule prepared before study initiation

Setting: multicentre (USA only)

Duration: 16 weeks

Participants

123 participants enrolled (BtA group $=92 ;$ placebo group $=28$ )
Placebo arm: 28 participants (18 dropouts: 64\%); 19 participants were female and 9 were male; median age was 62 years (range: 45 to 82); ethnicity: 26 participants were Caucasian, 1 was African-American, 1 was Asian, none were Hispanic, none were other ethnicity; mean duration of symptoms not stated; mean BDS score at baseline: not stated

$\mathrm{BtA}$ (Dysport) 40 units/eye: 30 participants (7 dropouts: 23\%); 21 participants were female and 9 were male; median age was 66 years (range: 35 to 82); ethnicity: 27 were Caucasian, 1 was African-American, 1 was Asian, none were Hispanic, none were other ethnicity; mean duration of symptoms not stated; mean BDS score at baseline: not stated

BtA(Dysport) 80 units/eye: 31 participants ( 6 dropouts: 19\%); 24 participants were female and 7 were male; median age was 67 years (range: 45 to 80); ethnicity: 28 participants were Caucasian, 2 were African-American, 1 was Asian, none were Hispanic, none were other ethnicity; mean duration of symptoms not stated; mean BDS score at baseline: not stated

BtA(Dysport) 120 units/eye: 31 participants (4 dropouts: 13\%); 25 participants were female and 6 were male; median age was 62 years (range: 33 to 91); ethnicity: 24 participants were Caucasian, 1 was African-American, 1 was Asian, 2 were Hispanic, 2 participants were other ethnicity; mean duration of symptoms not stated; mean BDS score at baseline: not stated

\section{Inclusion criteria:}

- bilateral benign essential blapharospasm - defined as a focal dystonia of no known etiology, exhibiting sustained or repetitive involuntary spasm of the muscles of the upper face

- age $\geq 18$ years

- symptomatic onset at least 6 months before baseline visit

- minimum score of 8 on the Blepharospasm Disability Scale

- BtA naive and non-naive people were accepted, as long as non-naive were BtA free for at least 12 weeks

\section{Exclusion criteria:}

- BtA non-naive people who had not been BtA free for at least 12 weeks

- neuroleptic associated blepharospasm; isolated levator dysfunction or eyelid apraxia

- previous myectomy or neurectomy; people receiving anti-spastic and muscle-relaxant medication or neuromuscular joint affecting medication on the 30 days previous to the baseline visit unless taken at a constant dose throughout the study

- concomitant BtA injections at a site other than the orbicularis oculi muscles

- people receiving investigational drugs or devices within 30 days prior to the baseline visit, or were expecting to receive such a drug or device over the study period

- current ophthalmologic infection, a disease of the neuromuscular junction, such as myasthenia gravis or related muscle disorders, or any condition where an intramuscular injection was contraindicated

- women with a positive urine pregnancy test, who were pregnant or lactating, and those of childbearing potential who were not practicing an efficient method of contraception

- hypersensitivity to BtA or other components of the test materials, or if they had a history of, or were currently abusing, drugs or alcohol 
Truong 2008 (Continued)

Interventions
Participants were randomly assigned to one of 4 groups: placebo, 40 units/eye, 80 units/eye, 120 units/ eye. The process was completed by an investigator not involved in treatment administration nor participant assessment. A total volume of $0.1 \mathrm{~mL}$ of Dysport or placebo was injected subcutaneously in each of the 6 injections sites in the region of the orbicularis oculi muscle. Each participant received only one treatment in each eye.

BtA: Xeomin (incobotulinumtoxinA)

Placebo: The reconstituted volume of placebo was equivalent to the reconstituted volume for the 120 units study group.

Study drug preparation: Dysport (abobotulinumtoxinA) was prepared by reconstituting 500 units of freeze-dried toxin with $2.5 \mathrm{ml}$ of sodium chloride $0.9 \%$ to provide a concentration of $200 \mathrm{units} / \mathrm{mL}$. A volume of reconstitute containing the appropriate number of units per study group $(40,80$, or 120 units) was drawn up into a $1.0 \mathrm{~mL}$ syringe, which was filled with sodium chloride $0.9 \%$ up to a total volume of $0.6 \mathrm{~mL}$

EMG guidance: no information

- percentage of normal activity on the Blepharospasm Disability Scale

\section{Secondary outcomes:}

- functional disability

- Frequency on Involuntary Movement scale

- severity of oculofacial spasms rated using the Severity Rating Scale

- adverse events

Notes This study was supported by funding from Ipsen Ltd.

\section{Risk of bias}

\begin{tabular}{|c|c|c|}
\hline Bias & Authors' judgement & Support for judgement \\
\hline $\begin{array}{l}\text { Random sequence genera- } \\
\text { tion (selection bias) }\end{array}$ & Low risk & $\begin{array}{l}\text { "Eligible patients were allocated sequential numbers before being randomly } \\
\text { assigned to one of the four treatment groups according to a computer-gener- } \\
\text { ated randomization schedule prepared before study initiation" }\end{array}$ \\
\hline $\begin{array}{l}\text { Allocation concealment } \\
\text { (selection bias) }\end{array}$ & Low risk & $\begin{array}{l}\text { "A pack containing one vial of study medication (active treatment or placebo, } \\
\text { identical in size and appearance) was allocated to each patient. Reconstitu- } \\
\text { tion of treatments was prepared by a third party, who was not involved with } \\
\text { patient management or assessments" }\end{array}$ \\
\hline $\begin{array}{l}\text { Blinding of participants } \\
\text { and personnel (perfor- } \\
\text { mance bias) } \\
\text { All outcomes }\end{array}$ & Low risk & $\begin{array}{l}\text { "A pack containing one vial of study medication (active treatment or placebo, } \\
\text { identical in size and appearance) was allocated to each patient. Reconstitu- } \\
\text { tion of treatments was prepared by a third party, who was not involved with } \\
\text { patient management or assessments. Investigators were blinded to the treat- } \\
\text { ment dose and type of treatment throughout the study" }\end{array}$ \\
\hline $\begin{array}{l}\text { Blinding of outcome as- } \\
\text { sessment (detection bias) } \\
\text { Objective outcomes }\end{array}$ & Unclear risk & $\begin{array}{l}\text { Although all study personnel were stated to be blinded, the high proportion of } \\
\text { dropouts in the placebo group (64\%) suggests it was possible that the rating } \\
\text { investigator identified the treatment group }\end{array}$ \\
\hline $\begin{array}{l}\text { Blinding of outcome as- } \\
\text { sessment (detection bias) } \\
\text { Subjective outcomes }\end{array}$ & Unclear risk & $\begin{array}{l}\text { Although all study personnel were stated to be blinded, the high proportion of } \\
\text { dropouts in the placebo group (64\%) suggests it was possible that the rating } \\
\text { investigator identified the treatment group }\end{array}$ \\
\hline
\end{tabular}


Truong 2008 (Continued)

Incomplete outcome data High risk The large proportion of dropouts in the placebo group (64\%) might have in(attrition bias) duced a clinically relevant bias

All outcomes

\begin{tabular}{|c|c|c|}
\hline $\begin{array}{l}\text { Selective reporting (re- } \\
\text { porting bias) }\end{array}$ & Low risk & $\begin{array}{l}\text { The expected outcomes that are usually evaluated in intervention trials for } \\
\text { this condition were reported in this study }\end{array}$ \\
\hline
\end{tabular}

Enriched population - pre- Low risk dominant enrolment of The inclusion and exclusion criteria do not make any reference to previous repositive responders sponse to Botox

\begin{tabular}{|c|c|c|}
\hline $\begin{array}{l}\text { Enriched population - ex- } \\
\text { clusion of poor responders }\end{array}$ & High risk & $\begin{array}{l}\text { "Patients were not eligible for inclusion in the study if they had isolated levator } \\
\text { dysfunction or eyelid apraxia" }\end{array}$ \\
\hline
\end{tabular}

For-profit bias High risk $\quad$ Study funding supported by Ipsen

JRS: Jankovic Rating Scale

BSDI: Blepharospasm Disability Index

Characteristics of excluded studies [ordered by study ID]

\begin{tabular}{|c|c|}
\hline Study & Reason for exclusion \\
\hline Aramideh 1995 & Not randomised \\
\hline Boyle 2009 & No placebo group \\
\hline Fahn 1985 & Unclear if this was a randomised trial or not. Primary outcome was neurophysiological \\
\hline Frueh 1988 & $\begin{array}{l}\text { It enrolled } 26 \text { participants with blepharospasm in a randomised, double-blind trial comparing BtA } \\
\text { to placebo. All participants received BtA in the upper eyelids and only the lower eyelids were ran- } \\
\text { domised to BtA or placebo. It was not possible to compare BtA versus placebo }\end{array}$ \\
\hline Girlanda 1996 & Unclear if this was a randomised trial or not. Primary outcome was neurophysiological \\
\hline Iwashige 1995 & No placebo group \\
\hline Jankovic 1987 & $\begin{array}{l}\text { Participants were randomised by a toss of a coin to BtA or placebo. Although } 12 \text { participants had } \\
\text { blepharospasm, only } 3 \text { of them did not have additional involuntary movements of the face or neck. } \\
\text { Ineligible population }\end{array}$ \\
\hline Jankovic 1995 & Not randomised. No placebo group \\
\hline Mezaki 1995 & No placebo group \\
\hline Mezaki 1999 & No placebo group \\
\hline Nussgens 1997 & No placebo group \\
\hline Pagan 2018 & Duplicate of Mitsikostas 2018 \\
\hline Park 1993 & $\begin{array}{l}\text { Only } 4 \text { participants with blepharospasm were enrolled in the blinded controlled phase. The report } \\
\text { gave no clear data comparing the BtA and placebo groups containing these } 4 \text { participants. No us- } \\
\text { able study data }\end{array}$ \\
\hline
\end{tabular}




\begin{tabular}{ll}
\hline Study & Reason for exclusion \\
\hline Price 1997 & No placebo group \\
\hline Sampaio 1997 & No placebo group \\
\hline
\end{tabular}

\section{DATA AND ANALYSES}

\section{Comparison 1. Botulinum toxin type $A$ (BtA) versus placebo}

\begin{tabular}{|c|c|c|c|c|}
\hline Outcome or subgroup title & $\begin{array}{l}\text { No. of } \\
\text { studies }\end{array}$ & $\begin{array}{l}\text { No. of } \\
\text { partici- } \\
\text { pants }\end{array}$ & Statistical method & Effect size \\
\hline $\begin{array}{l}\text { 1.1 Blepharospasm-specific } \\
\text { severity }\end{array}$ & 3 & & Mean Difference (IV, Random, 95\% CI) & $0.93[0.61,1.25]$ \\
\hline $\begin{array}{l}\text { 1.2 Blepharospasm-specific dis- } \\
\text { ability }\end{array}$ & 3 & 290 & Mean Difference (IV, Random, 95\% Cl) & $0.69[0.18,1.19]$ \\
\hline 1.3 Adverse events & 2 & 169 & Risk Ratio (M-H, Fixed, 95\% Cl) & $1.18[0.87,1.60]$ \\
\hline $\begin{array}{l}1.4 \text { Vision complaints (diplop- } \\
\text { ia, blurred vision, visual distur- } \\
\text { bance) }\end{array}$ & 2 & 228 & Risk Ratio (M-H, Fixed, 95\% Cl) & $5.73[1.79,18.36]$ \\
\hline 1.5 Eyelid ptosis & 3 & 289 & Risk Ratio (M-H, Fixed, 95\% Cl) & $4.02[1.61,10.00]$ \\
\hline 1.6 Increased lacrimation & 2 & 228 & Risk Ratio (M-H, Fixed, 95\% Cl) & $2.04[0.46,9.13]$ \\
\hline 1.7 Xerophthalmia & 2 & 228 & Risk Ratio (M-H, Fixed, 95\% Cl) & $1.83[0.69,4.86]$ \\
\hline $\begin{array}{l}\text { 1.8 Frequency of ble- } \\
\text { pharospasm-specific involuntary } \\
\text { movements }\end{array}$ & 2 & & Std. Mean Difference (IV, Random, 95\% CI) & $0.79[0.31,1.27]$ \\
\hline $\begin{array}{l}\text { 1.9 Subjective participant evalua- } \\
\text { tion }\end{array}$ & 2 & 170 & Std. Mean Difference (IV, Fixed, 95\% CI) & $0.86[0.53,1.20]$ \\
\hline 1.10 Tolerability - dropouts & 2 & 169 & Risk Ratio (M-H, Fixed, 95\% Cl) & $1.44[0.31,6.79]$ \\
\hline
\end{tabular}


Analysis 1.1. Comparison 1: Botulinum toxin type A (BtA) versus placebo, Outcome 1: Blepharospasm-specific severity

$\begin{array}{lccccc}\text { Study or Subgroup } & \text { MD } & \text { SE } & \text { Weight } & \text { IV, Random, 95\% CI } & \text { Mean Difference } \\ \text { IV, Random, 95\% CI }\end{array}$

\begin{tabular}{lrrrr}
\hline Jankovic 2011 & 0.7599 & 0.2218 & $45.6 \%$ & $0.76[0.33,1.19]$ \\
Mitsikostas 2018 & 1.5694 & 0.5073 & $9.8 \%$ & $1.57[0.58,2.56]$ \\
Truong 2008 & 0.9639 & 0.2249 & $44.6 \%$ & $0.96[0.52,1.40]$
\end{tabular}

Total $(95 \%$ CI $)$

$100.0 \%$

$0.93[0.61,1.25]$

Heterogeneity: $\mathrm{Tau}^{2}=0.01 ; \mathrm{Chi}^{2}=2.20, \mathrm{df}=2(\mathrm{P}=0.33) ; \mathrm{I}^{2}=9 \%$

Test for overall effect: $\mathrm{Z}=5.77(\mathrm{P}<0.00001)$

Test for subgroup differences: Not applicable

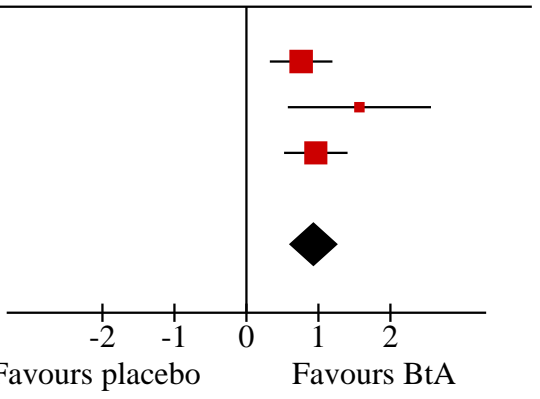

Analysis 1.2. Comparison 1: Botulinum toxin type A (BtA) versus placebo, Outcome 2: Blepharospasm-specific disability

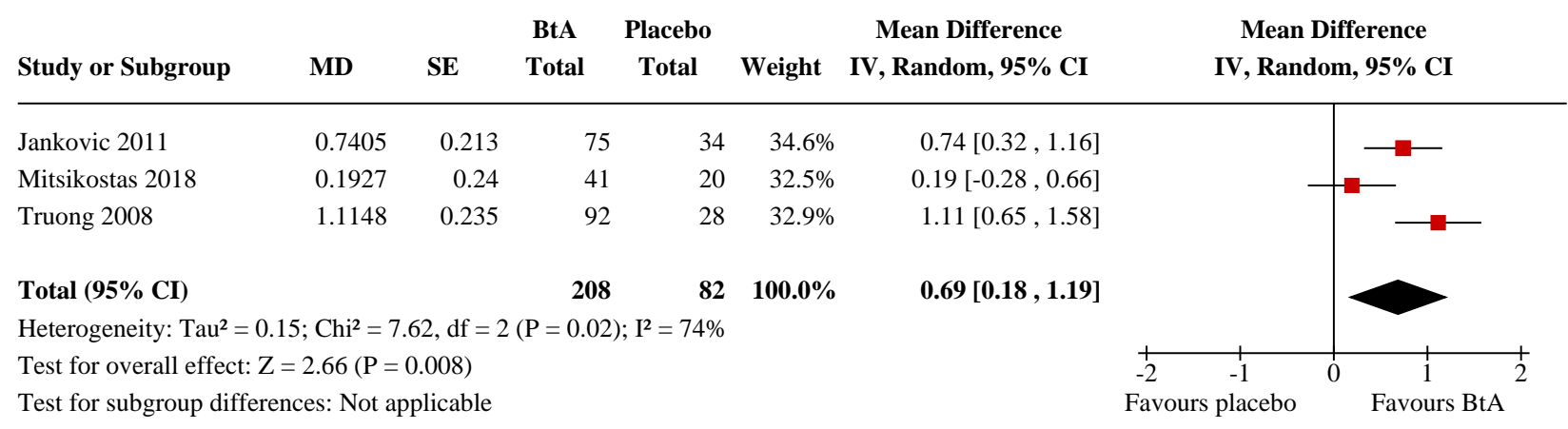

Analysis 1.3. Comparison 1: Botulinum toxin type A (BtA) versus placebo, Outcome 3: Adverse events

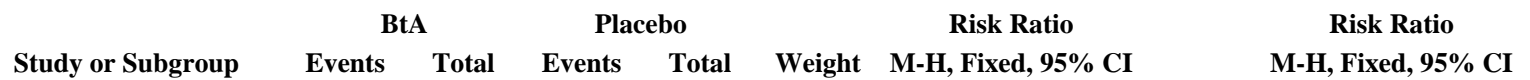

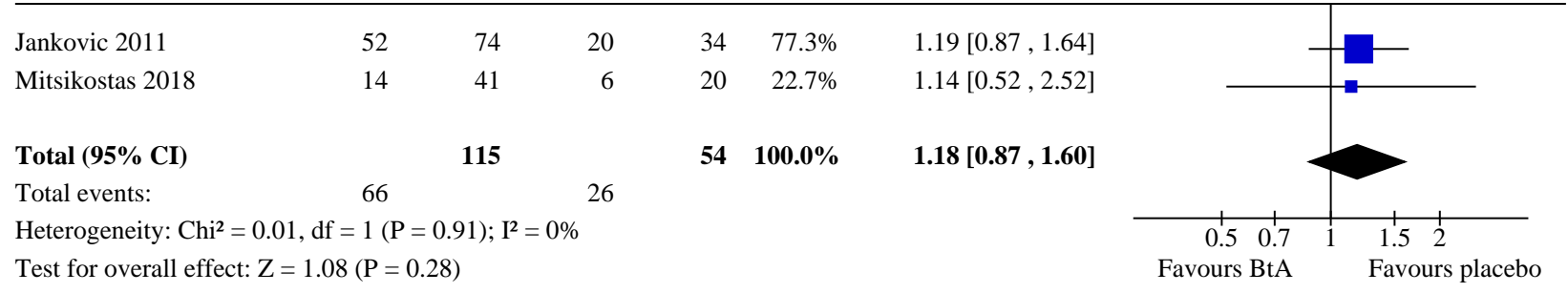


Analysis 1.4. Comparison 1: Botulinum toxin type $A(B t A)$ versus placebo, Outcome 4: Vision complaints (diplopia, blurred vision, visual disturbance)

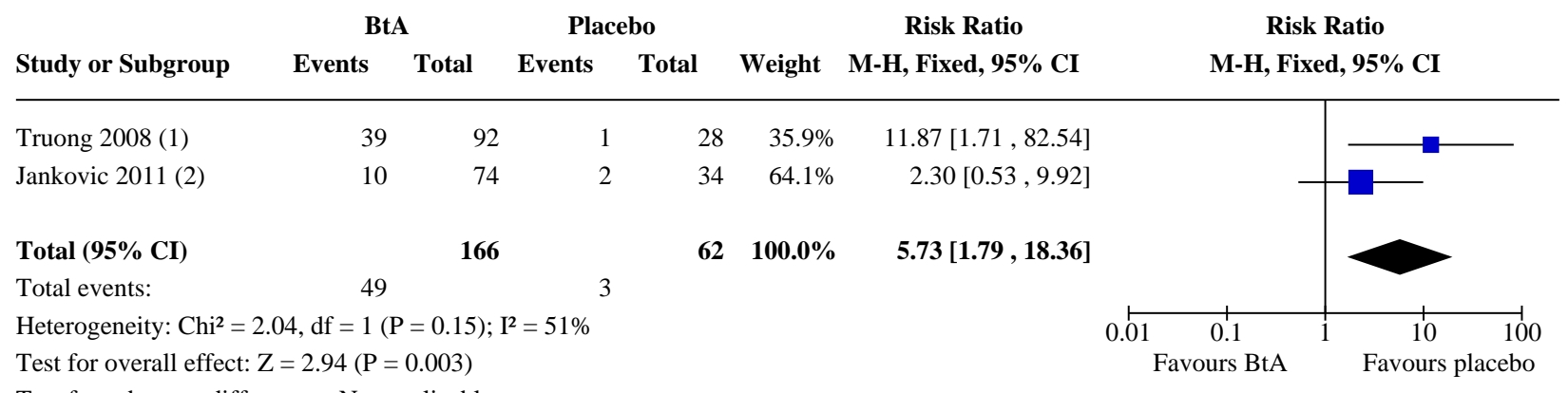

Test for subgroup differences: Not applicable

\section{Footnotes}

(1) blurred vision + diplopia

(2) visual disturbance + blurred vision

\section{Analysis 1.5. Comparison 1: Botulinum toxin type A (BtA) versus placebo, Outcome 5: Eyelid ptosis}

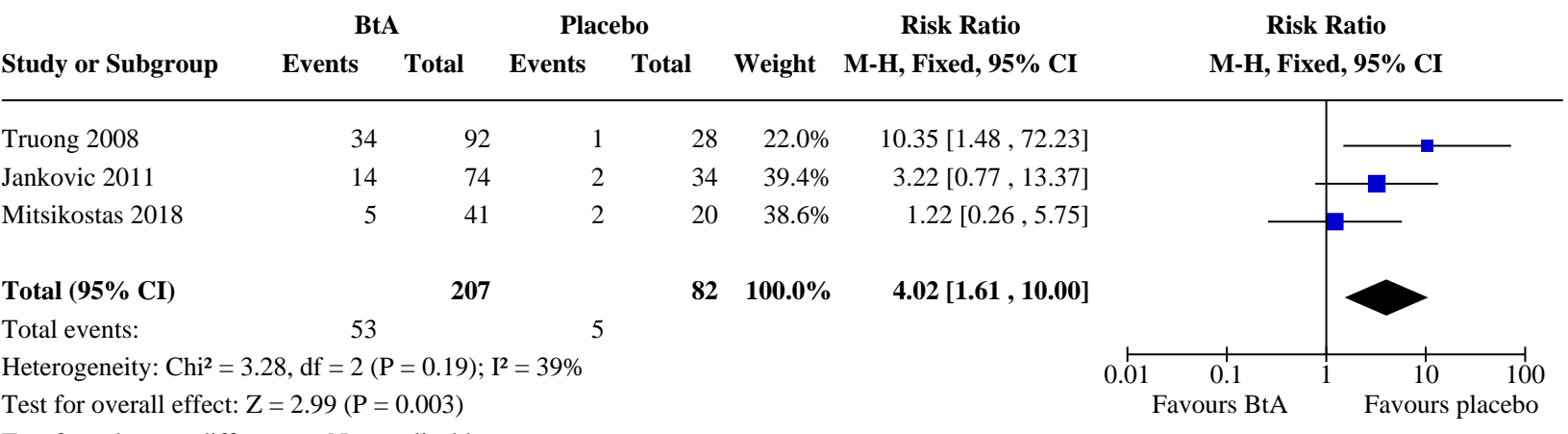

Test for subgroup differences: Not applicable

Analysis 1.6. Comparison 1: Botulinum toxin type A (BtA) versus placebo, Outcome 6: Increased lacrimation

BtA

Study or Subgroup
Placebo

Total Events Tota
Risk Ratio

Weight M-H, Fixed, 95\% CI
Risk Ratio

M-H, Fixed, 95\% CI

\begin{tabular}{|c|c|c|c|c|c|c|}
\hline Truong 2008 & 10 & 92 & 1 & 28 & $52.8 \%$ & $3.04[0.41,22.75]$ \\
\hline Jankovic 2011 & 2 & 74 & 1 & 34 & $47.2 \%$ & $0.92[0.09,9.79]$ \\
\hline Total $(95 \%$ CI $)$ & & 166 & & 62 & $100.0 \%$ & $2.04[0.46,9.13]$ \\
\hline Total events: & 12 & & 2 & & & \\
\hline \multicolumn{7}{|c|}{ Heterogeneity: $\mathrm{Chi}^{2}=0.59, \mathrm{df}=1(\mathrm{P}=0.44) ; \mathrm{I}^{2}=0 \%$} \\
\hline \multicolumn{7}{|c|}{ Test for overall effect: $\mathrm{Z}=0.93(\mathrm{P}=0.35)$} \\
\hline Test for subgroup & Jot a & able & & & & \\
\hline
\end{tabular}

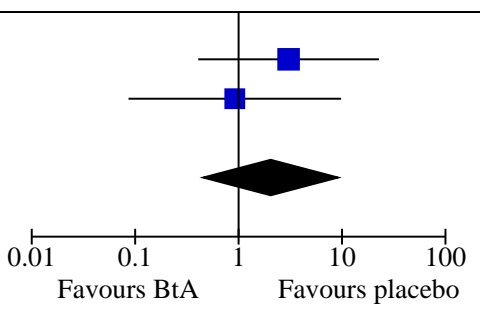


Analysis 1.7. Comparison 1: Botulinum toxin type A (BtA) versus placebo, Outcome 7: Xerophthalmia

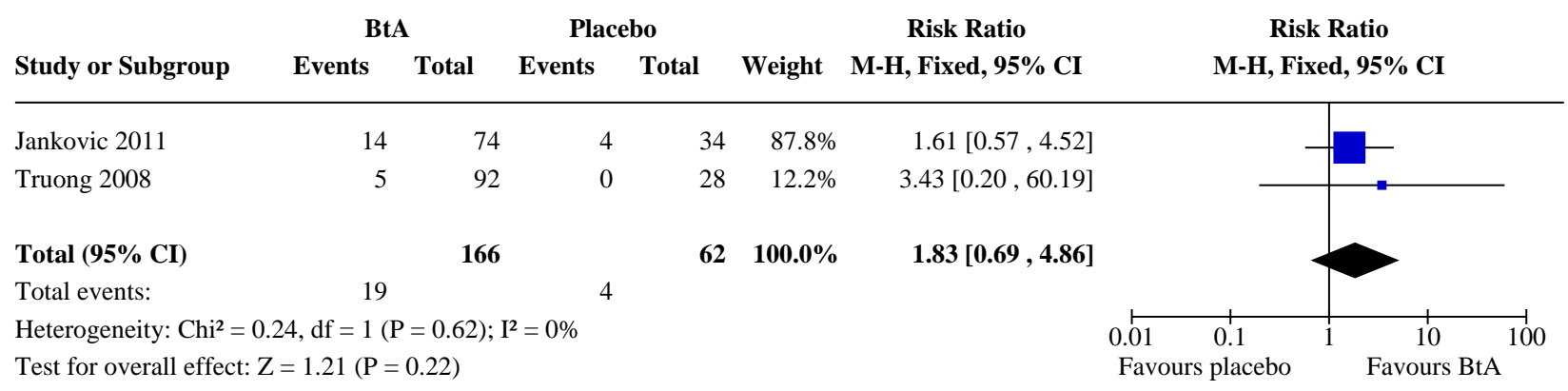

Test for subgroup differences: Not applicable

Analysis 1.8. Comparison 1: Botulinum toxin type $A(B t A)$ versus placebo, Outcome 8: Frequency of blepharospasm-specific involuntary movements

\begin{tabular}{|c|c|c|c|c|c|}
\hline tudy or Subgroup & SMD & SE & Weight & $\begin{array}{l}\text { Std. Mean Difference } \\
\text { IV, Random, 95\% CI }\end{array}$ & $\begin{array}{l}\text { Std. Mean Difference } \\
\text { IV, Random, 95\% CI }\end{array}$ \\
\hline
\end{tabular}

\begin{tabular}{lrrrr}
\hline Jankovic 2011 & 0.5607 & 0.2103 & $52.4 \%$ & $0.56[0.15,0.97]$ \\
Truong 2008 & 1.05 & 0.2359 & $47.6 \%$ & $1.05[0.59,1.51]$
\end{tabular}

Total $(95 \%$ CI $)$

$100.0 \%$

$0.79[0.31,1.27]$

Heterogeneity: $\mathrm{Tau}^{2}=0.07 ; \mathrm{Chi}^{2}=2.40, \mathrm{df}=1(\mathrm{P}=0.12) ; \mathrm{I}^{2}=58 \%$

Test for overall effect: $\mathrm{Z}=3.25(\mathrm{P}=0.001)$

Test for subgroup differences: Not applicable

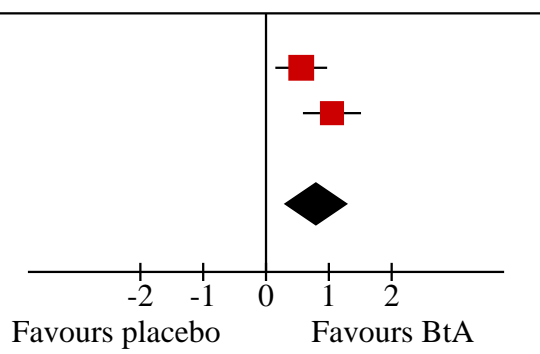

Analysis 1.9. Comparison 1: Botulinum toxin type A (BtA) versus placebo, Outcome 9: Subjective participant evaluation

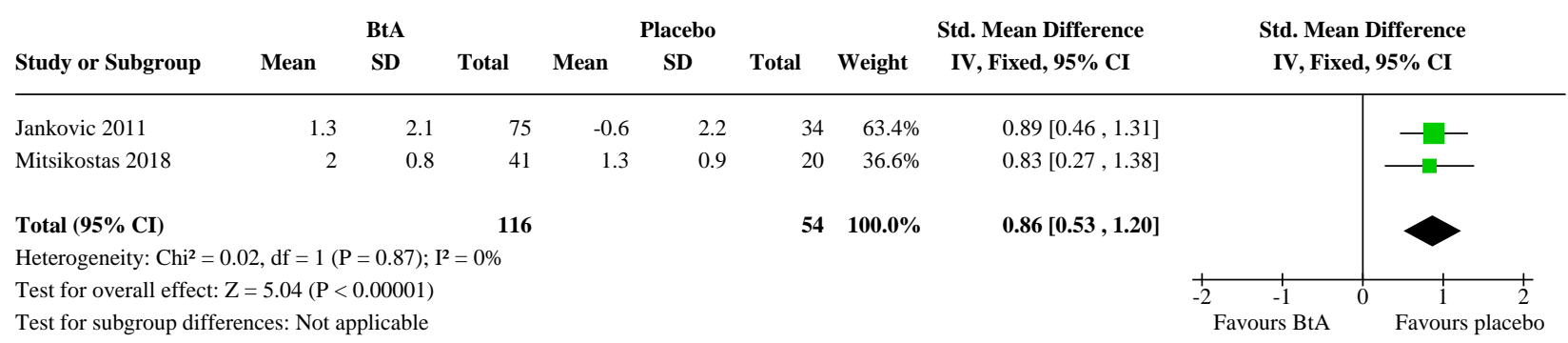




\section{Analysis 1.10. Comparison 1: Botulinum toxin type A (BtA) versus placebo, Outcome 10: Tolerability - dropouts}

\begin{tabular}{|c|c|c|c|c|c|c|c|c|}
\hline \multirow[b]{2}{*}{ Study or Subgroup } & \multicolumn{2}{|c|}{ BtA } & \multicolumn{2}{|c|}{ Placebo } & \multirow[b]{2}{*}{ Weight } & \multirow{2}{*}{$\begin{array}{c}\text { Risk Ratio } \\
\text { M-H, Fixed, 95\% CI }\end{array}$} & \multirow{2}{*}{\multicolumn{2}{|c|}{$\begin{array}{c}\text { Risk Ratio } \\
\text { M-H, Fixed, 95\% Cl }\end{array}$}} \\
\hline & Events & Total & Events & Total & & & & \\
\hline Jankovic 2011 & 1 & 74 & 1 & 34 & $50.5 \%$ & $0.46[0.03,7.13]$ & & \\
\hline Mitsikostas 2018 & 5 & 41 & 1 & 20 & $49.5 \%$ & $2.44[0.30,19.51]$ & & \\
\hline Total $(95 \%$ CI $)$ & & 115 & & 54 & $100.0 \%$ & $1.44[0.31,6.79]$ & & \\
\hline Total events: & 6 & & 2 & & & & & \\
\hline \multirow{2}{*}{\multicolumn{4}{|c|}{$\begin{array}{l}\text { Heterogeneity: } \mathrm{Chi}^{2}=0.91, \mathrm{df}=1(\mathrm{P}=0.34) ; \mathrm{I}^{2}=0 \% \\
\text { Test for overall effect: } \mathrm{Z}=0.46(\mathrm{P}=0.65)\end{array}$}} & & & & $0.01 \quad 0.1$ & 10 \\
\hline & & & & & & & Favours BtA & Favours \\
\hline
\end{tabular}

\section{APPENDICES}

\section{Appendix 1. CENTRAL search strategy}

\#1 MeSH descriptor: [Botulinum Toxins] explode all trees

\#2 Botulinum Toxins, Type A

\#3 (botul* near/2 tox $\left.{ }^{\star}\right):$ ti,ab

\#4 (botox or dysport or xeomin or myobloc or rimabotulinum* or abobotuli* or onabotulinum* or oculinum or purtox or CNBTX or Neuronox):ti,ab

\#5 $\{$ or \#1-\#4\}

\#6 MeSH descriptor: [Dystonic Disorders] explode all trees

\#7 MeSH descriptor: [Dystonia] explode all trees

\#8 MeSH descriptor: [Torticollis] explode all trees

\#9 MeSH descriptor: [Blepharospasm] explode all trees

\#10 MeSH descriptor: [Meige Syndrome] explode all trees

\#11 MeSH descriptor: [Hemifacial Spasm] explode all trees

\#12 (cervic* near/2 dysto*):ti,ab

\#13 blepharosp*:ti,ab

\#14 (hem* near/2 spasm*):ti,ab

\#15 (meige and (dysto* or syndrom)):ti,ab

\#16 (crani* near/2 dysto*):ti,ab

\#17 (foca* near/2 dysto*):ti,ab

\#18 (write* and (cramp* or dysto*)):ti,ab

\#19 torticol*:ti,ab

$\# 20$ or \#6-\#19\}

$\# 21 \# 5$ and \#20

\#22 MeSH descriptor: [Animals] explode all trees 
\#23 MeSH descriptor: [Humans] explode all trees

\#24 \#22 not \#23

\#25 \#21 not \#24 in Trials

\section{Appendix 2. MEDLINE search strategy}

\#1 randomized controlled trial.pt.

\#2 controlled clinical trial.pt.

\#3 randomized.ab.

\#4 placebo.ab.

\#5 clinical trials as topic.sh.

\#6 randomly.ab.

\#7 trial.ti.

\#8 1 or 2 or 3 or 4 or 5 or 6 or 7

\#9 exp botulinum toxins/

\#10 exp botulinum toxins, type $\mathrm{A} /$

\#11 (botul\$ adj2 tox\$).ti,ab.

\#12 (botox or dysport or xeomin or myobloc or rimabotulinum\$ or abobotuli\$ or onabotulinum\$ or oculinum or purtox or CNBTX or Neuronox).ti,ab.

$\# 139$ or 10 or 11 or 12

\#14 (cervic\$ adj2 dysto\$).ti,ab.

\#15 blepharosp\$.ti,ab.

\#16 (hem\$ adj2 spasm\$).ti,ab.

\#17 (meige and (dysto\$ or syndrom\$)).ti,ab.

\#18 (crani\$ adj2 dysto\$).ti,ab.

\#19 (foca\$ adj2 dysto\$).ti,ab.

\#20 (write\$ and (cramp\$ or dysto\$)).ti,ab.

\#21 torticol\$s.ti,ab.

\#22 exp dystonic disorders/

\#23 exp dystonia/

\#24 exp torticollis/

\#25 exp blepharospasm/

\#26 exp meige syndrome/

\#27 exp hemifacial spasm/

\#28 14 or 15 or 16 or 17 or 18 or 19 or 20 or 21 or 22 or 23 or 24 or 25 or 26 or 27

\#29 8 and 3 and 28

\#30 exp animals/ not humans/ 
\#31 29 not 30

\section{Appendix 3. Embase search strategy}

$\# 1$ random\$.tw.

\#2 clinical trial:.mp.

\#3 placebo\$.mp.

\#4 double-blind\$̦.tw.

\#5 1 or 2 or 3 or 4

\#6 exp Hemifacial Spasm/

\#7 exp Meige Syndrome/

\#8 exp blepharospasm/

\#9 exp torticollis/

\#10 exp Dystonia/

\#11 exp Dystonic Disorders/

\#12 (cervic\$ adj2 dysto\$).ti,ab.

\#13 blepharosp\$.ti,ab.

\#14 (hem\$ adj2 spasm\$).ti,ab.

\#15 (meige and (dysto\$ or syndrom\$)).ti,ab.

\#16 (crani\$ adj2 dysto\$).ti,ab.

$\# 17$ (foca\$ adj2 dysto\$).ti,ab.

\#18 (write\$ and (cramp\$ or dysto\$)).ti,ab.

\#19 torticol\$.ti,ab.

\#20 5 or 6 or 7 or 8 or 9 or 10 or 11 or 12 or 13 or 14 or 15 or 16 or 17 or 18

\#21 exp Botulinum Toxins, Type A/

\#22 exp Botulinum Toxins/

\#23 (botul\$ adj2 tox\$).ti,ab.

\#24 (botox or dysport or xeomin or myobloc or rimabotulinum\$ or abobotuli\$ or onabotulinum\$ or oculinum or purtox or CNBTX or Neuronox).ti,ab.

\#25 21 or 22 or 23 or 24

\#26 19 and 20 and 25

\#27 limit 26 to human

WHAT'S NEW

\begin{tabular}{lll}
\hline Date & Event & Description \\
\hline 15 October 2020 & $\begin{array}{l}\text { New citation required and conclusions } \\
\text { have changed }\end{array}$ & $\begin{array}{l}\text { Three new trials, enrolling a combined were included in this up- } \\
\text { dated review (Jankovic 2011; Mitsikostas 2018; Truong 2008) }\end{array}$ \\
\hline
\end{tabular}




\begin{tabular}{lll}
\hline Date & Event & Description \\
\hline 25 July 2020 & New search has been performed & $\begin{array}{l}\text { Three new trials, enrolling a combined were included in this up- } \\
\text { dated review (Jankovic 2011; Mitsikostas 2018; Truong 2008) }\end{array}$ \\
\hline
\end{tabular}

\section{HISTORY}

Protocol first published: Issue 3, 2004

Review first published: Issue 1, 2005

\begin{tabular}{lll}
\hline Date & Event & Description \\
\hline 8 June 2019 & $\begin{array}{l}\text { New citation required but conclusions } \\
\text { have not changed }\end{array}$ & $\begin{array}{l}\text { New authorship, accumulation of changes, re-assessment and } \\
\text { rewriting according to new reporting standards, addition of a } \\
\text { 'Summary of findings' table }\end{array}$ \\
\hline 6 October 2008 & Amended & Converted to new review format. \\
\hline 25 December 2003 & $\begin{array}{l}\text { New citation required and conclusions } \\
\text { have changed }\end{array}$ & Substantive amendment \\
\hline
\end{tabular}

\section{CONTRIBUTIONS OF AUTHORS}

A Peter Moore - APM; Cristina Sampaio - CS; Filipe Brogueira Rodrigues - FBR; Gonçalo S Duarte - GSD; João Costa - JC; Joaquim Ferreira - JJF; Mafalda Castelão - MC; Raquel E Marques - REM.

Conceiving the review - APM, CS, JC, JJF

Designing the review - APM, CS, JC, JJF

Co-ordinating the review - JC

Designing search strategies - FBR, JC

Undertaking searches - FBR, GSD

Screening search results - FRB, GSD, MF, REM

Organising retrieval of papers - FRB, GSD, JC, MF, REM

Screening retrieved papers against eligibility criteria - FRB, GSD, MF, REM

Appraising quality of papers - FRB, GSD, JC, MF, REM

Extracting data from papers - FRB, GSD, JC, MF, REM

Writing to authors of papers for additional information - GSD, JC, REM

Data management for the review - FRB, GSD, MF, REM

Entering data into RevMan 5 - FRB, GSD, MF, REM

Analysis of data - FRB, GSD, JC, MF, REM

Interpretation of data - APM, CS, FRB, GSD, JC, JJF, MF, REM

Writing the review - FRB, GSD, JC, MF, REM

Providing general advice on the review - CS, JC, JJF 
Performing previous work that was the foundation of the current review - Ana Borges, Claudia Espírito Santo, Miguel Coelho

\section{DECLARATIONS OF INTEREST}

JC, JJF, and CS were investigators in clinical trials for the use of botulinum toxin A and B in dystonia, sponsored by Elan (manufacturer of botulinum toxin type B), Allergan (manufacturer of botulinum toxin type A), and Ipsen (manufacturer of botulinum toxin type A). Searching for studies, selection of studies, data extraction and analysis (including risk of bias), and GRADE assessment were performed by review authors (FBR, GSD, MC, REM) who were not trialists. JJF and CS were speakers in symposia promoted by Elan, Allergan, and Ipsen.

APM has received royalties from Ipsen for the use of the 'LIVEchart' scoring system for botulinum toxin treatment efficacy. In addition, he has received consulting fees from Ipsen, Merz (manufacturer of botulinum toxin type A), Eisai (manufacturer of botulinum toxin type B), and Allergan. The same companies have provided support for travel to meetings for studies or other purposes.

\section{SOURCES OF SUPPORT}

\section{Internal sources}

- Cochrane Movement Disorders Group, Portugal

- The Walton Centre for Neurology and Neurosurgery, UK

\section{External sources}

- National Institute for Health Research (NIHR), UK

This review update is funded by the National Institute for Health Research (NIHR) [SRPG Project: 16/114/26 Clinically effective treatments for central nervous system disorders in the NHS, with a focus on epilepsy and Movement Disorders]. The views expressed are those of the author(s) and not necessarily those of the NIHR or the Department of Health and Social Care.

\section{DIFFERENCES BETWEEN PROTOCOLANDREVIEW}

For this updated review, we restricted the included study design to parallel-group. We made no changes to the type of participants or interventions allowed.

We included adverse events, which we originally listed as secondary outcomes, as primary safety outcomes. In this safety analysis, we also considered the proportion of participants with the most frequent adverse events, not stated in the original protocol. We included assessments of the frequency of blepharospasm-specific involuntary movements; the duration of effect, and proportion of participants who dropped out due to adverse drug reactions, as new secondary outcomes measures.

New approaches were assumed to deal with missing data and unit of analysis issue.

We used the latest recommended Cochrane tool for assessing risk of bias in this review, which we expanded to include two additional criteria. Blinding of outcome assessment was analysed in two new subcategories: subjective and objective assessment.

We also added a 'Summary of findings table'.

\section{INDEX TERMS}

\section{Medical Subject Headings (MeSH)}

Blepharospasm [ ${ }^{\star}$ drug therapy]; Botulinum Toxins, Type A [ ${ }^{*}$ therapeutic use]; Neuromuscular Agents [ ${ }^{*}$ therapeutic use]; Randomized Controlled Trials as Topic

\section{MeSH check words}

Humans 